\title{
Where can introduced populations learn their tricks? Searching for the geographical source of a species introduction to the Galápagos archipelago
}

\author{
Andrea S. Sequeira ${ }^{1}$ (D) Adrienne Cheng ${ }^{1} \cdot$ Sarah Pangburn $^{1} \cdot$ Adrián Troya $^{2}$
}

Received: 2 November 2016 / Accepted: 6 June 2017

(c) Springer Science+Business Media B.V. 2017

\begin{abstract}
We seek to understand the potential genetic impact of introduced species in an ecosystem where conservation efforts and pressure from development co-occur: the Galápagos Archipelago. To date, the introduced weevil Galapaganus h. howdenae is found only in Santa Cruz Island; however it has recently expanded its range beyond the Agricultural Zone into the highlands. We are focusing on comparisons between continental and introduced populations to clarify whether the current genetic patterns in introduced populations can reflect recovery from a past bottleneck and predict its invasive potential. A second objective is to narrow down the geographic source of the introduction and confirm their origin from a single introduction pulse. We found comparable microsatellite genetic diversity featuring many island-specific alleles, but reduced mitochondrial haplotype diversity in the islands. Additionally, both markers showed signals of population expansion and homogeneously distributed variation in the introduced range, in contrast to structured continental populations. The addition of mitochondrial sequences to the microsatellite dataset in the Approximate Bayesian Computation analyses (DIYABC) favors a single introduction pulse from the Northern Manabí area; a scenario that is in agreement with the haplotype network. An origin from higher elevation
\end{abstract}

Electronic supplementary material The online version of this article (doi:10.1007/s10592-017-0988-9) contains supplementary material, which is available to authorized users.

Andrea S. Sequeira

asequeir@wellesley.edu

1 Department of Biological Sciences, Wellesley College, 106 Central Street, Wellesley, MA 02481, USA

2 Escuela Politécnica Nacional (Instituto de Ciencias Biológicas), Quito, Ecuador habitats provides clues about the environmental amplitude of the naturalized populations. However, given that a large percentage of the microsatellite variation in island populations is due to new island alleles, the answer to the question "where can introduced populations learn their tricks?" could be: right at their new location.

Keywords Single introduction pulse $\cdot$ Population expansion · Introduction scenarios · Highland origin of founders $\cdot$ Recovered microsatellite diversity

\section{Introduction}

Species invasions of continental habitats rarely are accompanied by the total exclusion of native competitors. Island systems, on the other hand, are more vulnerable because they are seemingly less saturated or the native species are seemingly less competitive (Simberloff 1986). While oceanic islands are natural models for studying the process of generation of species diversity (Emerson and Kolm 2005), such endemic diversity may be threatened by the introduction of exotic species. We seek to understand the potential genetic impact of one introduced species in an ecosystem where conservation efforts and pressure from development co-occur: the Galápagos Archipelago. Invasive species from nearby continental areas have been identified as the principal threat to the terrestrial ecosystems of the Galápagos islands (Snell et al. 2002a, b). Since humans first arrived to Galápagos in 1535, the rate of insect introductions has been almost one new insect species per year with an increase of $59 \%$ in the number of unintentional introductions since 1998 (Peck et al. 1998; Causton et al. 2006). The central islands of the archipelago, with the most human activity and transport with the mainland have 
accumulated the most introduced species (Peck et al. 1998; Causton et al. 2006).

Examples of recent insect introductions into the islands include the predatory wasp Polistes versicolor (Abedrabbo 1991; Abedrabbo et al. 1991), the cottony cushion scale Icerya purchasi, and the little fire ant Wasmannia auropunctata (Roque Albelo and Causton 1999). The impact of each of these introduced species on the endemic and native flora and fauna varies (Roque Albelo et al. 2003; Grant et al. 2005; Wagner and Van Driesche 2010; Traveset et al. 2013), as do the strategies to attempt to control or eradicate them. A successful biological control program was implemented to stem populations of the cottony cushion scale across the archipelago (Causton et al. 2004; Lincango et al. 2011; Alvarez et al. 2012; Hoddle et al. 2013), and an intensive eradication program was employed to curve the establishment and expansion of the little fire ant in Marchena island (Causton et al. 2005). Less aggressive insect invaders, such as the one highlighted in this study, have not prompted any species-specific intervention, but have collectively raised awareness and informed management actions to avoid accidental inter-island transfer (Roque Albelo et al. 2006).

The introduced weevil Galapaganus h. howdenae was first found on Santa Cruz Island in 1992 (Causton et al. 2006). Even though G. h. howdenae is capable of flight (Lanteri 2004), to date it has only been found in one island. Among the ten flightless Galapaganus species that are endemic to the archipelago, some inhabit neighboring islands, such as G. conwayensis, endemic to Santa Cruz, Pinta, and Northern Isabela, while others have very restricted ranges, such as G. ashlocki, endemic to the highlands of Santa Cruz (Lanteri 1992; Peck 2006). The continental distribution of G. h. howdenae encompasses lowlands of mainland Ecuador and Perú (Lanteri 2004). In the introduced range in Galápagos, its geographic range appears to be expanding beyond the Agricultural Zone into higher elevations (Sequeira Pers. Comm.) where vegetation has already been most affected by humans (Watson et al. 2010). Additionally, the feeding preferences of this recently introduced insect now include endangered endemic host plants at low and high elevations (Boada 2005). Endemic and introduced Galapaganus populations share life history traits (Lanteri 1992), such as aspects of their reproductive biology and preferred host plants (specifically in the highlands of Santa Cruz), but differ in their patterns of genetic structure (Sequeira et al. 2012) and history and timing of colonization or introduction into the islands (Sequeira et al. 2000, 2008a; Mok et al. 2014).

Introduced species can undergo a drastic reduction in population size resulting in decreased genetic flexibility that is possibly detrimental to its adaptive potential (Nei et al. 1975; Garza and Williamson 2001; Allendorf and
Lundquist 2003; Colautti et al. 2005). However, the loss of variability can be mitigated through introductions from multiple genetically differentiated sources (Facon et al. 2008), demographic expansions (Zenger et al. 2003; Kolbe et al. 2004), or effective population connectivity that could improve their overall fitness (Lindholm et al. 2005).

The genetic effects of introduced populations on their native counterparts, by means of breakdown of effective behavioral reproductive barriers, can range from increased vigor to complete loss of fitness in the hybrids (Fitzpatrick and Shaffer 2007). In the weevil genus Galapaganus, no hybrids have been found between introduced $G$. h. howdenae and lowland endemics, and phylogenetic evidence points to well-defined species boundaries (Sequeira et al. 2008b). However, G. h. howdenae has expanded its range into the moist highlands, now sharing host plants with the single island endemic and highland specialist G. ashlocki. Preliminary estimates of unidirectional mitochondrial gene flow indicate significant gene flow from the introduced species into populations of the lowland endemic G. conwayensis, and from the highland endemic, G. ashlocki, into the introduced species (Pangburn et al. in prep). Single island endemics have restricted distributions and their survival could depend on effective reproductive isolation from close relatives. Additionally to its status as a single island endemic, G. ashlocki bears the added restriction of being a highland specialist, further constraining its suitable habitat and potentially raising its IUCN status to endangered.

The ecological effects of introduced species are harder to unravel (Evans 2004). In the Galapaganus system, the degree to which the introduced and endemic species compete for resources is still unclear; however as with other oligophagous insects (Berenbaum and Zangerl 1991), $G$. h. howdenae has shifted to feeding on the same host plants as their endemic counterparts. In the case of native widespread species, if the two species were to compete, it does not follow that the native species would be displaced (Leger and Espeland 2010). The potential ecological consequences from species introductions increase significantly for endemic species with restricted populations, or for those as $G$. ashlocki, that effectively function as isolated populations; in those cases, intervention, protection from introduced counterparts, and monitoring have been proposed as important components of the island native's continued survival (Cole et al. 2005; Garrett et al. 2007; Simbana and Tye 2009).

We have gained insight into the genetic patterns and timing of introduction of $G$. h. howdenae populations on Santa Cruz (Mok et al. 2014). Analyses of combined microsatellite genotypes from specimens in nine island localities showed evidence of past population size reductions. No evidence of admixture through multiple introductions was found, but introduced populations showed 
substantial current population sizes and genetic diversity comparable to long-established endemics. The time estimates for the introduction of $G$. h. howdenae support an accidental transfer during the colonization period (1832-1959), pre-dating the spurt in human population growth (1950-2001) (Mok et al. 2014).

At the time, little was known about the host preferences and genetic status of potential source populations within the native range in Ecuador, and samples from those locations were unavailable. We are now focusing on comparisons between source and introduced populations of $G$. h. howdenae, as well as increasing the geographic sampling within the introduced range to attempt to clarify whether the genetic patterns observed in island populations reflect recovery from a past bottleneck and are predictive of $G$. h. howdenae's invasive potential. The reservoir of genetic variability in this newly established populations could be similar or higher to that of continental populations and could indicate their potential for successful expansion beyond their present range. Such secondary invasions have been reported with other introductions that have turned into potent sources for invasions elsewhere (Kolbe et al. 2004).

A second objective is to use the sampling of the native range to narrow down the geographic source of this island introduction and confirm their origin due to a single introduction pulse. For this purpose, in addition to analyzing multi-locus microsatellite genotypes, we are interpreting results from an extensive mitochondrial sequences dataset. A combination of markers with contrasting modes of inheritance and rates of evolution might provide a more accurate understanding of a species' history (Flanders et al. 2009). The potential drawbacks of phylogeographic inference from mtDNA alone are well known (Flanders et al. 2009), but in combination with nuclear markers, the data can provide valuable understanding of a species' evolutionary trajectory (Lefebvre et al. 2016; Mende et al. 2016). In particular, it has been suggested that mitochondrial loci might reflect a more ancient evolutionary history (Edgington et al. 2016).

The investigation into the geographic origins of genetic variability across the native range will inform if multiple introductions are feeding this introduced species' genetic variability and pinpoint the geographic source of this introduction. In the short term, information regarding the distribution and amount of genetic variability in the introduced range could inform measures that attempt to control accidental inter-island transfer, while the narrowed geographic origins could offer clues on the adaptive amplitude of introduced populations. The longer-term impacts of these investigations could be in the form of insight into the genetic background of biological invasions.

\section{Materials and methods}

\section{Specimen collection, sampling effort and host preferences}

We obtained samples of $G$. h. howdenae weevils from thirteen localities across the Agricultural Zone (AZ) and National Park (NP) areas of Santa Cruz in the Galápagos archipelago and from eight localities in three regions in Manabí Province in Southwestern Ecuador (Fig. 1; Table 1). While sampling within the introduced range spans a large percentage of the island's area, given that we have added four marginal localities (Mok et al. 2014), the insect material obtained from the native range appears clustered with respect to the broader published range (Lanteri 2004). The number of specimens obtained in the native range is smaller than in the islands despite equal or larger collecting efforts. In addition to the samples detailed in Table 1, we explored a much larger area, approximately $250 \mathrm{~km}$ to the South in Guayas Province (Bosque Protector Cerro Blanco and Reserva Manglares Churute) and $300 \mathrm{~km}$ to the North in Manabí Province (Jama Coaque Reserve).

In the native range, the most common host plants for $G$. h. howdenae were shrubs of Piper sp. (Cordoncillo), family Piperacea. In the introduced range, the main host plants were Erytrina sp., Guava and Aguacate. Weevils collected in El Chato and Los Gemelos (Fig. 1; Table 1) were found feeding on endemic Tournefortia rufoscericea and Scalesia pedunculata, alongside endemic congeners $G$. conwayensis and G. ashlocki. Adult weevil specimens were collected by beating on potential host vegetation and preserved in $100 \%$ ethanol at $-20^{\circ} \mathrm{C}$ until DNA was extracted.

Localities within the introduced range were grouped into Agricultural Zone (AZ) and National Park (NP) while those in the native range were grouped into Northern Manabí (NMB), Central Manabí (CMB) and Southern Manabí (SMB).

\section{DNA preparation, microsatellite validation and genotyping, and mitochondrial DNA sequencing}

We used three legs from each specimen to isolate DNA using the DNeasy Tissue Kit (Qiagen, Valencia, CA). We constructed two microsatellite libraries for this species using MseI and AseI restriction enzymes, following the FIASCO protocol (Fast Isolation by AFLP of Sequences COntaining repeats) (Zane et al. 2002; Stepien et al. 2010).

Microsatellite genotypes of each $G$. h. howdenae individual were obtained for eight polymorphic loci. Generally, amplification reactions were performed in a final volume of $10 \mu \mathrm{l}$ containing $1-2 \mu \mathrm{l}$ DNA template, $1 \mu \mathrm{l} 10 \times$ ThermoPol Reaction Buffer containing $2 \mathrm{mM} \mathrm{MgSO}_{4}$ (New England Biolabs), Taq polymerase (1 U) (New England 


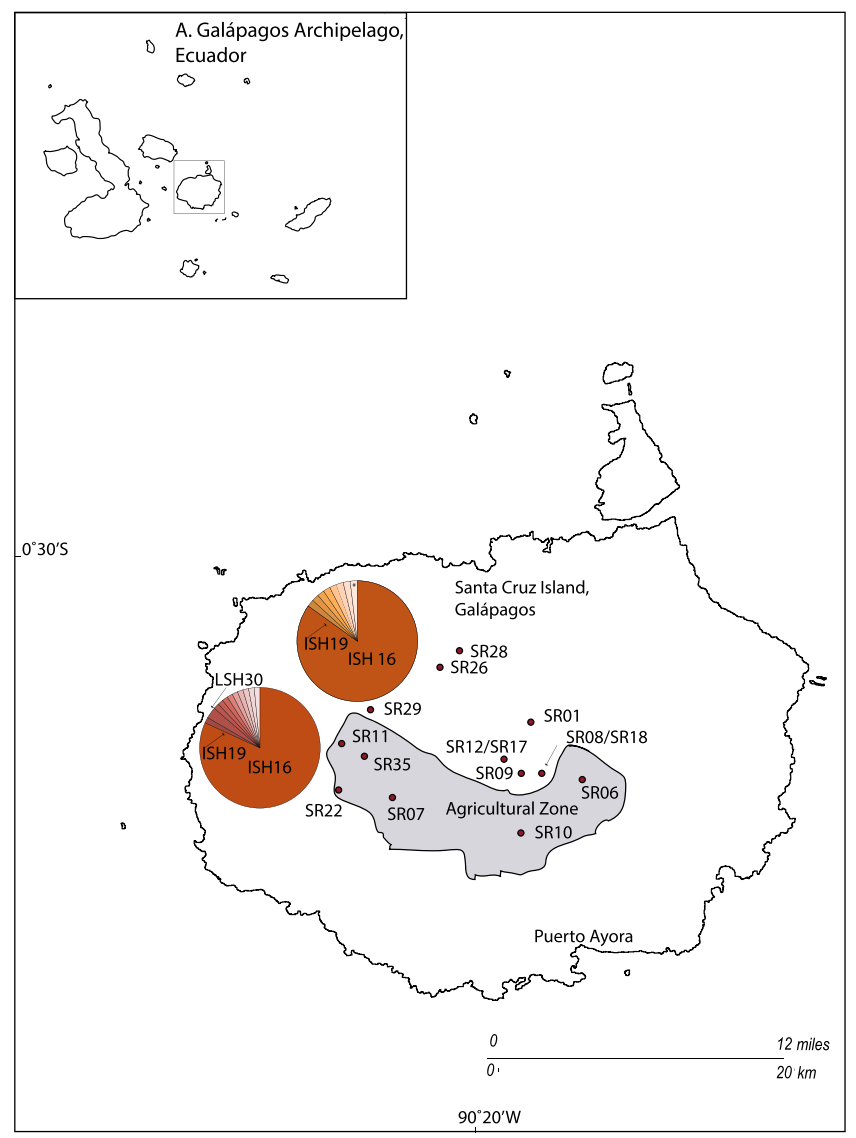

Fig. 1 Map of the two collecting areas for Galapaganus h. howdenae with localities, frequency and distribution of mitochondrial haplotypes. a Map of Santa Cruz Island in the Galápagos archipelago, shaded area marks the limits of the Agricultural Zone. Inset position of Santa Cruz within the archipelago. b Map of South Western Ecuador. Inset position of the area within Ecuador. Sampling locations

Biolabs), 0-3.0 $\mathrm{mM}$ of additional $\mathrm{MgCl}_{2}$, one fluorescently tagged forward primer $(5 \mu \mathrm{M}$; HEX, PET, 6FAM, NED from Applied Biosystems) and reverse primers $(5 \mu \mathrm{M})$, dNTPs (0.8 mM) (Invitrogen), and HPLC water. Optimal PCR cycling and reaction conditions for genotyping across the different polymorphic microsatellite loci are provided in Stepien et al. (2010). Quartets of PCR products were combined with LIZ600 or LIZ500 size standard (Applied Biosystems) and run on an ABI3100 Genetic Analyzer. GENEMAPPER version 4.3 was used to score positive reactions.

We routinely followed two approaches during the microsatellite data collection to maximize the validity and repeatability of the dataset (Mok et al. 2014; Sequeira et al. 2016). After the original microsatellite development and validation with a smaller number of samples (Stepien et al. 2010), samples that revealed alleles for the first time were re-genotyped in different multiplex combinations and blindly assigned to lab members for allele sizing. Only confirmed allele sizes (and therefore genotypes)

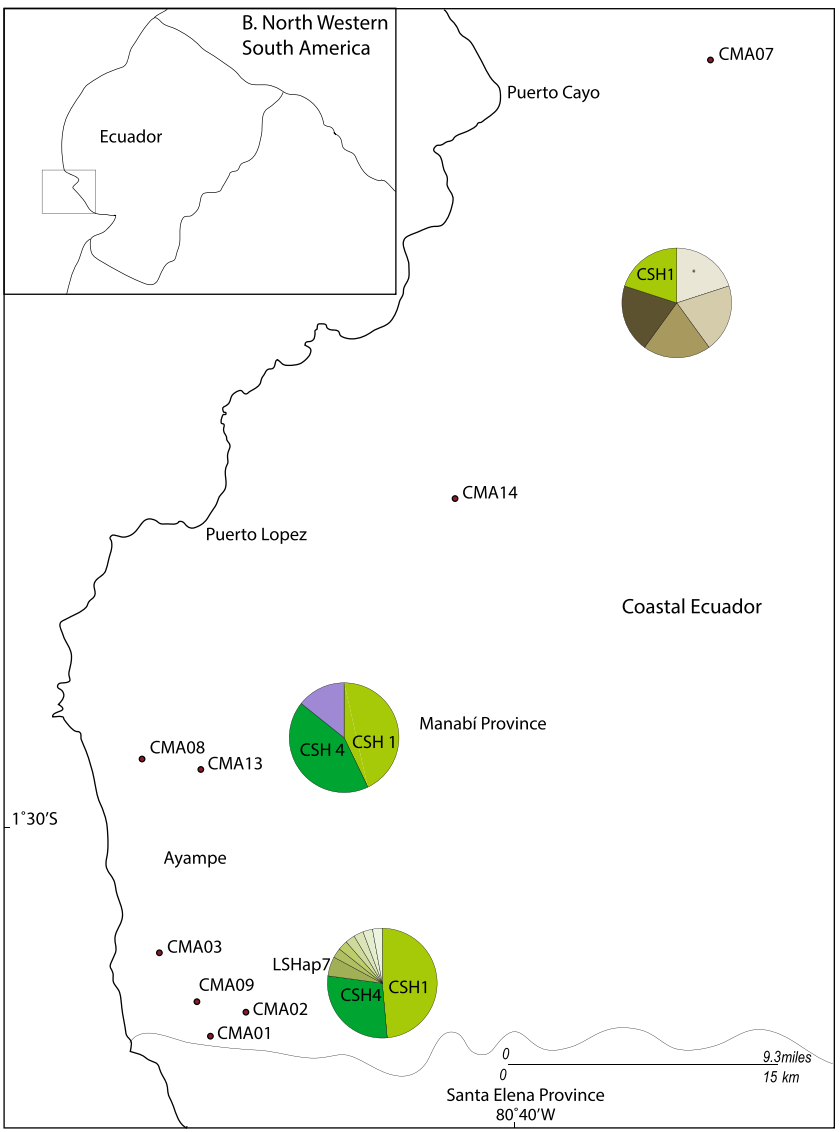

following locality codes in Table 1. Pie charts indicate proportional frequencies of shared and unique mitochondrial haplotypes in locality areas $\mathrm{CSH}$ continental shared haplotype, ISH island shared haplotype, $L S H$ locally shared haplotype, unique haplotypes are not labeled. Asterisks mark the continental and island haplotypes most closely linked in the TCS network

were incorporated to the final dataset. Additionally, after each locality was fully genotyped a small number of individual samples (between 5 and 7 depending on the locality) were randomly selected for re-genotyping and again blindly assigned to lab members for allele sizing.

After the microsatellite data collection was completed we tested the complete dataset with Microchecker (Oosterhout et al. 2004) to explore the presence of null alleles, large allele drop-out or scoring error due to stuttering. We also explored the possibility of deviations from Hardy Weinberg expectations for each locus in each of the two main regions (Continent and Island) using GenePop v4 (Raymond and Rousset 1995).

For estimates of mitochondrial haplotype diversity, haplotype network reconstruction and introduction scenario testing we obtained mitochondrial DNA sequences for three mitochondrial regions: Cytochrome Oxidase I and II and $12 \mathrm{~S}$ following protocols outlined by Sequeira et al. (2008a, b). One microlitre of a 1/10 dilution of genomic 
Table 1 List of sampling locations for Galapaganus h. howdenae weevil samples in Continental Ecuador and Santa Cruz Island, Galápagos (introduced range)

\begin{tabular}{|c|c|c|c|c|}
\hline Region/area & Population code & Location & Coordinates (altitude) & $\mathrm{N}$ (micro) \\
\hline \multirow[t]{6}{*}{ IS (AZ) } & SR10 & Road to Cerro Crocker & $00^{\circ} 41.324 \mathrm{~S}, 090^{\circ} 19.495 \mathrm{~W}(249 \mathrm{~m})$ & 15 \\
\hline & SR07 & Finca Steve Devine & $00^{\circ} 40.021 \mathrm{~S}, 090^{\circ} 24.192 \mathrm{~W}(351 \mathrm{~m})$ & 15 \\
\hline & SR11 & Above El Chato & $00^{\circ} 38.364 \mathrm{~S}, 090^{\circ} 25.605 \mathrm{~W}(422 \mathrm{~m})$ & $4(3)$ \\
\hline & SR22 & El Chato & $00^{\circ} 39.946 \mathrm{~S}, 090^{\circ} 26.383 \mathrm{~W}(106 \mathrm{~m})$ & 9 \\
\hline & SR06 & 2 km. N. of El Cascajo & $00^{\circ} 39.3735 \mathrm{~S}, 090^{\circ} 17.257 \mathrm{~W}(240 \mathrm{~m})$ & $15(14)$ \\
\hline & SR35 & Salasaca & $00^{\circ} 37.855 \mathrm{~S}, 090^{\circ} 26.233 \mathrm{~W}(377 \mathrm{~m})$ & 7 \\
\hline \multirow[t]{7}{*}{ IS (NP) } & SR08/SR18 & Media Luna & $00^{\circ} 40.11 \mathrm{~S}, 090^{\circ} 19.438 \mathrm{~W}(469 \mathrm{~m})$ & $13(12)$ \\
\hline & SR09 & Miconia zone & $00^{\circ} 39.9685 \mathrm{~S}, 090^{\circ} 19.503 \mathrm{~W}(505 \mathrm{~m})$ & 6 \\
\hline & SR12/SR17 & La Caseta & $00^{\circ} 39.499 \mathrm{~S}, 090^{\circ} 19.659 \mathrm{~W}(614 \mathrm{~m})$ & 14 \\
\hline & SR01 & Cerro Croker trail & $00^{\circ} 39.998 \mathrm{~S}, 090^{\circ} 19.68 \mathrm{~W}(800 \mathrm{~m})$ & 15 \\
\hline & SR26 & Close to Los Gemelos & $00^{\circ} 37.762 \mathrm{~S}, 090^{\circ} 23.320 \mathrm{~W}(597 \mathrm{~m})$ & 5 \\
\hline & SR28 & Los Gemelos & $00^{\circ} 37.554 \mathrm{~S}, 090^{\circ} 23.106 \mathrm{~W}(611 \mathrm{~m})$ & $12(14)$ \\
\hline & SR29 & West end of Agricultural Zone & $00^{\circ} 37.962 \mathrm{~S}, 090^{\circ} 26.134 \mathrm{~W}(369 \mathrm{~m})$ & 8 \\
\hline \multirow[t]{4}{*}{$\mathrm{CO}(\mathrm{SMB})$} & CMA01 & Close to Ayampe & $01^{\circ} 42.666 \mathrm{~S}, 80^{\circ} 46.750 \mathrm{~W}(62 \mathrm{~m})$ & 7 \\
\hline & CMA02 & Road after Ayampe & $01^{\circ} 41.866 \mathrm{~S}, 80^{\circ} 46.766 \mathrm{~W}(184 \mathrm{~m})$ & 8 \\
\hline & CMA03 & Road to Atamari & $01^{\circ} 38.666 \mathrm{~S}, 80^{\circ} 46.766 \mathrm{~W}(129 \mathrm{~m})$ & 12 \\
\hline & CMA09 & On E15, Cerro Lobo & $01^{\circ} 40.366 \mathrm{~S}, 80^{\circ} 47.700 \mathrm{~W}(170 \mathrm{~m})$ & $5(8)$ \\
\hline \multirow[t]{2}{*}{$\mathrm{CO}(\mathrm{CMB})$} & CMA08 & Road to Jocotoco Reserve & $01^{\circ} 40.516 \mathrm{~S}, 80^{\circ} 48.500 \mathrm{~W}(30 \mathrm{~m})$ & 6 \\
\hline & CMA13 & End of road to Jocotoco reserve & $01^{\circ} 40.650 \mathrm{~S}, 80^{\circ} 47.583 \mathrm{~W}(34 \mathrm{~m})$ & 1 \\
\hline \multirow[t]{2}{*}{ CO (NMB) } & CMA07 & Road between Puerto Cayo and Jipijapa, km 12 & $01^{\circ} 20.250 \mathrm{~S}, 80^{\circ} 39.566 \mathrm{~W}(431 \mathrm{~m})$ & 2 \\
\hline & CMA14 & PN Machalilla, Bola de Oro trail (way to La Mocora) & $01^{\circ} 36.350 \mathrm{~S}, 80^{\circ} 43.900 \mathrm{~W}(410 \mathrm{~m})$ & 3 \\
\hline
\end{tabular}

Sampling locations with collecting areas and locality codes following Fig. 1, IS indicates island and CO indicates contiental localities GPS data and altitude in meters $(\mathrm{m})$ and number of specimens studied (if numbers differ between the microsatellite and mitochondrial dataset, the number in parenthesis indicates the number of mitochondrial sequences)

DNA was amplified to produce double-stranded products for the three gene regions. Purified amplification products were sequenced using the BigDye v3.1 terminator protocol (Applied Biosystems) using PCR primers in an ABI3100 Genetic Analyzer. Protein coding sequences were edited and aligned in Sequencher v. 4.5 (GeneCodes corporation, Ann Arbor, MI) while $12 \mathrm{~S}$ alignments were produced in Clustal W (Chenna et al. 2003).

\section{Genetic analyses}

\section{Genetic diversity and population size changes within localities and within each region}

We calculated the average number of alleles (A) and of expected heterozygosity $\left(\mathrm{H}_{\mathrm{e}}\right)$ across all microsatellite loci and all localities within the two main regions (Continent: CO and Santa Cruz Island: IS) using ArLeQuin 3.5 (Excoffier et al. 2005). We compiled the results through Box plots using BoxPlotR (boxplot.tyerslab.com). We reported mean and median values for each region as averages across localities and loci, and for each microsatellite locus as averages across localities within each region. Statistical differences between region means were assessed using non-parametric Wilkoxon, Krustalis-Wallis tests in Jmp 11.1. Median values were contrasted using notches within the graphical $\mathrm{R}$ interface; notches are defined $\pm 1.58 \times \mathrm{IQR} / \mathrm{sqrt}$ (n) representing the $95 \%$ confidence interval of each median (Chambers et al. 1983). Medians with non-overlapping 95\% CI are reported as significantly different.

Allelic frequencies for microsatellite loci for each region were obtained using GeNEPOP 4.0 (Raymond and Rousset 1995). To compare allelic frequency distributions across the two regions, alleles from all loci were compiled and classified as shared or region-specific. Statistical differences between the frequency distributions of lost and gained alleles and of increases and decreases in frequency of shared alleles were calculated through non parametric Wilcoxon/Kruskal Wallis rank sum tests (Kruskal and Wallis 1952).

To incorporate measures of effective population size and changes of population size over time based on the microsatellite data we recorded the values of $\left(\theta_{\mathrm{H}}\right)$ (assuming constant mutation rate and the stepwise mutation model) using ARLEQuin 3.5 and recorded M ratios for the continental areas and the region as a whole. The software program M (Garza and Williamson 2001) was used to calculate the 
$\mathrm{M}$ ratios and significant deviations from equilibrium situations. Statistical differences between $\left(\theta_{\mathrm{H}}\right)$ region averages were calculated following the same procedures used for genetic diversity estimates. Procedures for analyses using M follow recommendations outlined by Peery et al. (2012) and detailed in Mok et al. (2014).

We assessed mitochondrial haplotype diversity within areas and regions in different ways: by the number and frequency of unique and shared haplotypes, by differences between haplotype sequences within each region, and by haplotype indexes per area and region. Haplotype diversity (Hd) and nucleotide diversity per site $(\pi)$ for each region analyzed as a single group were calculated in DNAsp v5 (Librado and Rozas 2009), and standard molecular indexes such as nucleotide diversity averaged over all loci and pairwise differences between haplotypes within localities, and averaged across all localities in each region were calculated using ARLequin 3.5. Statistical differences between region averages were calculated following the same procedures used for microsatellite genetic diversity estimates.

Estimates of population size, changes of population size over time, and the potential for populations expansions using the mitochondrial sequence dataset were explored through calculations of $\theta_{w}$ from the total number of mutations, Tajima's D (Tajima 1989) and Fu and Li's F (Fu and Li 1993) using DNAsp v5.1 for each region and areas within the two regions.

\section{Differentiation between localities and regions}

We searched for signals of genetic structuring through analyses of molecular variance (Amova) using both datasets in parallel in ArLequin 3.5 (Excoffier et al. 2005). We performed the analyses as described by Weir and Cockerham (1984) estimating variance components and F-statistics analogues ( $\Phi$-statistics) for diversity at each level and testing $\Phi$-statistics' significance by 10,000 permutations (Cockerham and Weir 1984, 1987). The hierarchical distribution of genetic variance was assessed for all collecting localities grouped according to their region of origin (Continent or Island). Within each region, genetic variance was analyzed for localities grouped by area: in Santa Cruz grouping localities in the Agricultural Zone and National Park and in Continental Ecuador according to geographic proximity in Southern Manabí, Central Manabí and Northern Manabí.

To evaluate if there was consistently larger differentiation between localities in Continental Ecuador, as expected given the differences in times since establishment, we assessed the magnitude and significance of genetic differentiation across pairs of localities computing pairwise $\mathrm{F}_{\mathrm{ST}}$ indexes in ArLequin 3.5 (Excoffier et al. 2005) for each region. We examined the mean and median pairwise $\mathrm{F}_{\mathrm{ST}}$ values for localities within each area and the percentage of significant comparisons. Differences between mean and median values of the pairwise $\mathrm{F}_{\mathrm{ST}}$ indexes were compared following the same procedures used for genetic diversity estimates.

We used the software Structure v 2.3 (Pritchard et al. 2000; Hubisz et al. 2009) to analyze the microsatellite dataset with the purpose of assigning individuals to areas and to understand the potential for admixed origin of the island samples. The natural logarithm of the probability of the dataset was calculated over ten trials using a burnin of 10,000 and 90,000 replicates with either independent or correlated allele frequencies for all trials. The admixture and no admixture ancestry models were used in each case with and without sample group information to aid in the clustering (LocPrior function)(Hubisz et al. 2009). For all ancestry models, numbers of clusters $(\mathrm{K})$ between 1 and 10 were explored. The area groupings were used as locality priors under the LocPrior function given the subtle (and more marked) genetic structure detected between these units. We explored the possibility of multiple clusters analytically through DeltaK values following the Evanno method (Evanno et al. 2005). Structure results for all eight sets of runs (Admixture and No Admixture; correlated and independent allele frequencies; with and without addition of LocPrior) were summarized using Structure Harvester (Earl and Vonholdt 2012) while ClumpP (Jakobsson and Rosenberg 2007) and DistRuct (Rosenberg 2004) were used to visualize the results.

\section{Testing of introduction scenarios into Santa Cruz} and geographical source of $G$. h. howdenae populations

To distinguish between different introduction scenarios, we used DiYabc (Cornuet et al. 2014). We performed analyses on two datasets, the microsatellite (M) and a combined microsatellite and mitochondrial sequences dataset (C), with two population arrangements, one with five areas where AZ and NP were considered separately (v) and a four area arrangement where both island areas were analyzed as a single population (iv). Two groups of scenarios were considered for a total of twenty proposed introduction histories for the five area arrangement (Online Resource 1): a set where all island samples originated from a single source, either as one introduction pulse with subsequent differentiation in the islands or as sequential introductions from a single source (fourteen scenarios where introduction is proposed from each of the three continental areas with an alternating order of introduction in the two island areas), and a second set where two different continental areas are proposed as sources for the two island introductions (six scenarios). When we grouped the two island areas, the number 
of proposed introduction scenarios was reduced to five, including introductions from each continental area, from an ancestral source before differentiation of continental areas, and from an undifferentiated source pool. The four sets of analyses (Mv, Miv, Cv, Civ) were performed using uniform prior distributions and defined as follows: $1<N_{(1-5 \text { or } 1-4)}<10,000 ; 1<N f_{(1-5 \text { or } 1-4)}<100$; $1<\mathrm{db}<20 ; 1<t 1 \leq t 2 \leq t 3 \leq t 4$; where " $N$ " denotes the current effective population size, " $N f$ ' the effective number of founding individuals, "db" the bottleneck duration in generations, and " $t$ " the time in generations. For the microsatellite mutation model, priors were set to default values, which included the Generalized Stepwise Mutation model (Estoup et al. 2002) and a uniform prior distribution for the mean mutation rate. Summary statistics included the mean number of alleles, mean genic diversity, and mean size variance for both the "1-sample" and "2-sample" statistics. Additionally, we used the mean Garza-Williamson's M index ("1-sample statistic") as well as pairwise $F_{S T}$ values and the mean classification index ("2-sample statistics"). We simulated 10 million datasets for each analysis. We selected the optimal scenario from each analyses based on the posterior probabilities calculated through logistic regression on the $1 \%$ closest simulated datasets. We evaluated the confidence of the chosen scenario by generating pseudo-datasets and estimated type I errors as implemented in the program. We estimated the posterior distribution of parameters under the chosen scenario using the logit transformation and estimated parameter bias (mode of the mean relative bias: mmrb) and precision using 500 test datasets. An additional set of analyses was performed including scenarios where ghost populations were proposed as a source for the introduction following the same general parameters. However, the scenarios including ghost populations were never selected and the preferred scenarios did not differ from those selected in the four sets of analyses described.

Taking into account the differentiation among mitochondrial sequences between Continental localities and that some of that structure is associated with their geographic origin, we constructed a statistical parsimony haplotype network including all continental and island haplotypes. The objective was to explore the genetic relatedness among extant haplotypes, to identify which Continental haplotype/s were most similar to the island ones and pinpoint the likely geographic sources for this introduction. We used the software TCS (Clement et al. 2000) which collapses identical haplotypes and calculates the probability of parsimony. Based on a statistical assessment of mutations, minimum connections inferring genealogical relationships are made using a 95\% confidence assessment based on the conditional probability of the change of more than one nucleotide at a particular site.

\section{Results}

\section{Comparable microsatellite genetic diversity but reduced mitochondrial haplotype diversity in the introduced range}

After systematically applying the two sets of random regenotyping we incorporated all the validated loci into our final microsatellite dataset. Microchecker analysis of the eight loci included in the study showed no evidence for scoring error due to stuttering, large allele dropout or for null alleles. All eight loci showed no deviations from Hardy-Weinberg equilibrium within the two main areas under study (Online Resource 2).

Mean within-locality microsatellite diversity is not significantly reduced in the introduced region with respect to that of the continental area. The similarity in diversity between regions is found in the mean number of microsatellite alleles (A) $(\mathrm{p}=0.599)$ and expected heterozygosity $\left(H_{e}\right)$ per locus $(p=0.172)$ averaged across all localities (Fig. 2ai, ii). Median values for the number of alleles and expected heterozygosity from introduced localities were also not significantly lower than those from continental localities ( $\mathrm{p}=0.236$ and 0.165 respectively).

When contrasting microsatellite genetic variation per locus averaged across localities on the Continent and the Island, both measures display not significantly different values across five of the eight loci studied (Fig. 2bi, ii). Contrary to our expectations, the mean A values were significantly lower in the Continent region for one of the eight loci studied (locus 3, p <0.05), while the medians for continental localities were significantly lower for three loci (loci 2, 3, 4) (Fig. 2bi). Mean $\mathrm{H}_{\mathrm{e}}$ values per locus were also in general not significantly different between regions; only one locus displayed statistically significant lower mean values (locus $3, \mathrm{p}<0.05$ ), while an additional locus (locus 4) displayed significantly lower median values in the Continental localities (Fig. 2bii). In general, microsatellite genetic diversity within collecting sites does not appear reduced in the introduced region.

The total number of microsatellite alleles across the two regions is 59. Approximately half of the alleles within each region are shared, resulting in an equal proportion of shared to region-specific alleles in both regions (Fig. 3a). Differences in the standing frequencies of shared alleles are similarly distributed in both directions, such that there are no significant differences among the distribution of allelic frequency increases or decreases between regions $(p>0.05)$. In other words, there are 

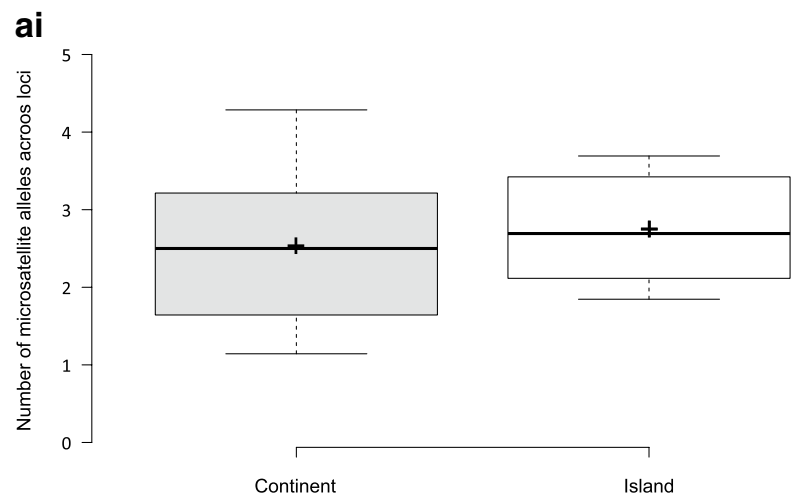

bi
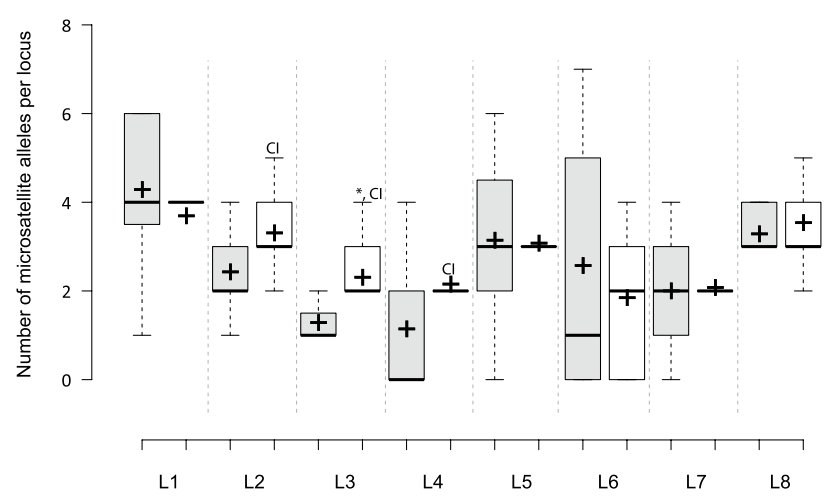

ci
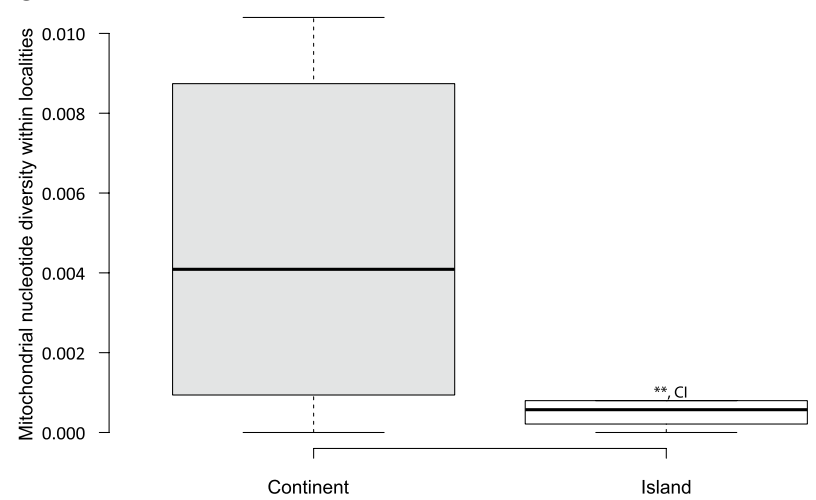

Fig. 2 Comparisons of microsatellite (a, b) and mitochondrial (c) genetic diversity within localities. Box plots display medians (solid line), means $(+)$ and maximum and minimum values (whiskers) for a number of alleles and expected heterozygosity averaged across all loci and all localities within each region (Continent vs. Santa Cruz Island). b Number of alleles and expected heterozygosity for each

similar numbers of alleles whose frequency increased and decreased, by comparable amounts, between regions (Fig. 3b). Most of the allelic frequency changes in either direction are skewed towards the smaller values so that, as expected, most of the allelic frequency changes were of small magnitude (0-0.2) with some exceptions where one continental allele has doubled its frequency and two have halved it, and a rare continental allele has almost aii
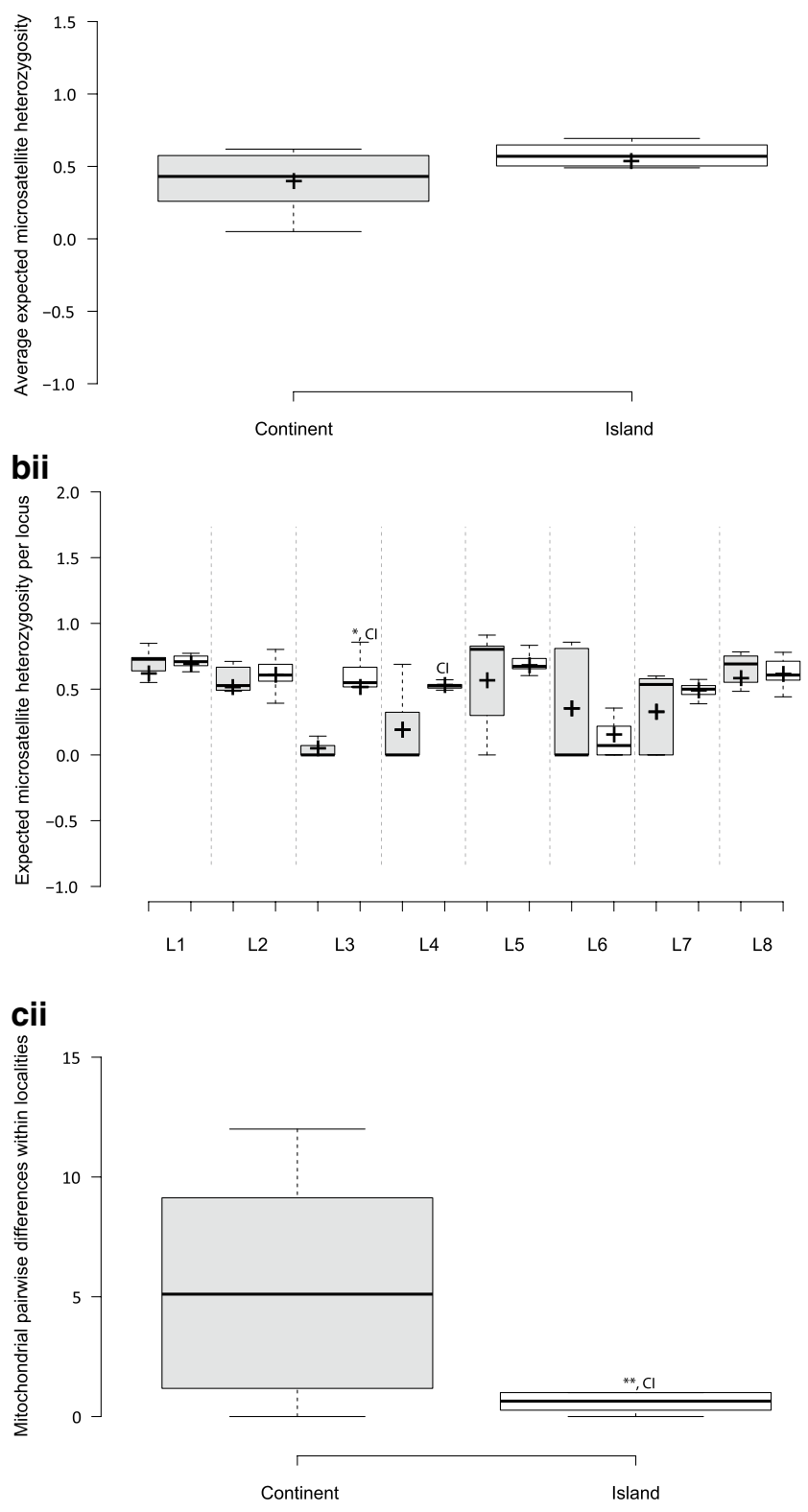

locus studied across localities. c Mitochondrial nucleotide diversity and pairwise differences within localities averaged across all localities in each region. Continent (light gray), Santa Cruz Island (white). Codes above the whiskers indicate levels of significance for differences between means $* * \mathrm{p}<0.01,{ }^{*} \mathrm{p}<0.05$, CI indicates non-overlapping $95 \%$ confidence intervals between medians

gained fixation in the Island region. When analyzing the patterns for region-specific alleles, the distributions of standing frequencies are again not significantly different $(p>0.05)$. In a sense, the frequency distribution of lost continental alleles, a majority of low frequency alleles with a few mid-frequency and high frequency alleles, is replaced by a new set of island alleles with a similar frequency distribution (Fig. 3c). In our view, 

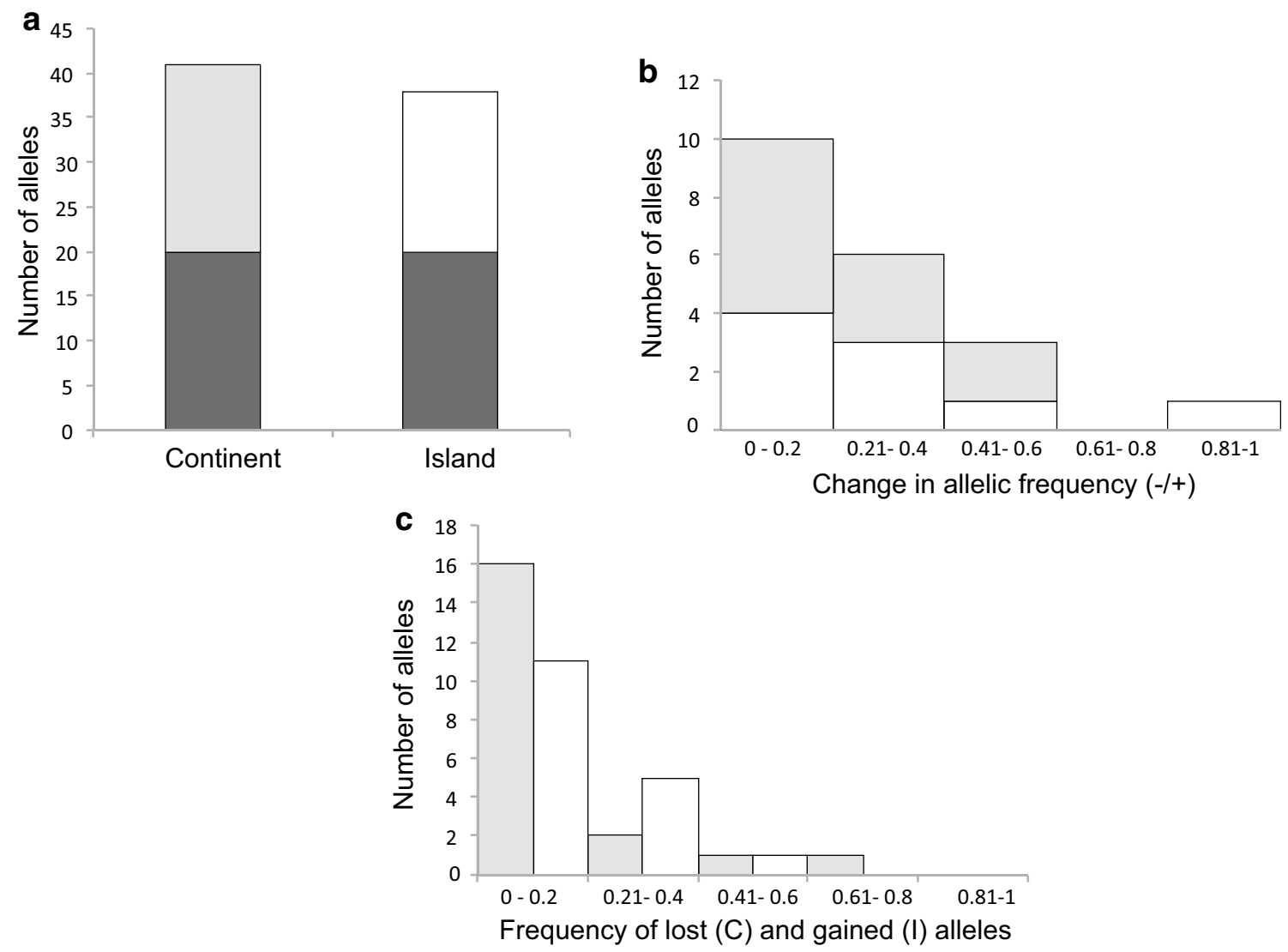

Fig. 3 Proportions of shared, lost and gained microsatellite alleles between continental and island regions and changes in frequency between regions. a Total number, shared and private alleles for each region, black shared alleles, gray and white alleles exclusive to each region. b Distribution of changes in allele frequency of shared alleles,

Table 2 Mitochondrial diversity per region and area

\begin{tabular}{lcll}
\hline Group & Nh (indiv) & Hd (SD) & $\pi \mathrm{i}(\mathrm{SD})$ \\
\hline IS all loc & $19(137)$ & $0.284(0.052)$ & $0.0019(0.0092)$ \\
AZ & $6(62)$ & $0.213(0.069)$ & $0.0002(0.0001)$ \\
NP & $15(74)$ & $0.345(0.073)$ & $0.0033(0.0016)$ \\
CO all loc & $16(47)$ & $0.811(0.041)$ & $0.0076(0.0005)$ \\
SMB & $10(35)$ & $0.743(0.056)$ & $0.0066(0.0004)$ \\
CMB & $3(7)$ & $0.714(0.127)$ & $0.0006(0.0001)$ \\
NMB & $5(5)$ & $1(0.126)$ & $0.0160(0.0021)$ \\
\hline
\end{tabular}

Numbers of unique mitochondrial haplotypes (Nh) per region and areas within, followed by the number of individuals carrying that haplotype, average haplotype diversity (Hd) and nucleotide diversity per site $(\pi \mathrm{i})$ and standard deviation for each region and area

these similarities in frequency distribution, and the parallel amounts of within locality genetic diversity, indicate that the introduced region has recovered its microsatellite diversity in numbers of alleles and mirrored the continental microsatellite frequency patterns. gray indicates frequency decreases from continent to island and white indicates frequency increases. c Distribution of allelic frequencies for lost (present in continent and not on island) and gained alleles (new to island), gray lost from continent, white gained on island

Numbers of mitochondrial haplotypes are similar in both regions, with 16 continental and 19 Island haplotypes. Haplotype diversity values (Hd) and nucleotide diversity per site per region $(\pi)$ are larger for the continental region (Table 2). Additionally, molecular diversity indexes calculated among mitochondrial haplotypes, as averages within each region, show significant differences between the Continent and Island regions, where the Island region displays significantly lower levels of mean nucleotide diversity averaged over all loci and mean pairwise differences between haplotypes within localities $(\mathrm{p}<0.01$, Fig. 2c). The introduced region harbors a comparable number of haplotypes as the continental region; however, those haplotypes appear to be less divergent. This is reiterated by the structure of the TCS haplotype network; within the introduced range most haplotypes (13 out of 19) are present only once and differ from a central and most frequent haplotype (ISH 16) by either one or two mutational steps (Fig. 6). 


\section{Lower population size with signals of population expansion after a bottleneck in the introduced range}

Values of $\left(\theta_{\mathrm{H}}\right)$ derived from microsatellite data are significantly lower in the island region compared to the source continental populations (mean $\theta_{\mathrm{HCO}}=1.78 \pm 0.42$, mean $\theta_{\mathrm{HIS}}=1.52 \pm 0.03, \mathrm{p}=0.01$ ) suggesting larger population sizes in the source region. Microsatellite derived $\mathrm{M}$ ratios for island areas calculated with this augmented dataset did not differ from those previously published (Mok et al. 2014) and continue to point to a past reduction in population size possibly related to the introduction event. On the other hand, microsatellite markers indicate stable equilibrium populations in continental areas and the continental region as a whole (Table 3 ).

Similarly, the estimates of $\theta \mathrm{w}$ obtained from the mitochondrial dataset revealed larger values for the continental region $\left(\theta \mathrm{w}_{\mathrm{IS}}=0.0019, \theta \mathrm{w}_{\mathrm{CO}}=0.0077\right)$. Tajima's $\mathrm{D}$, and $\mathrm{Fu}$ and Li's $\mathrm{F}$ statistics using the mitochondrial dataset were negative and significant for the Island region and both island areas indicating an excess of recently derived haplotypes and suggesting that either population expansion or background selection has occurred (Fu and Li 1993). In contrast, all indexes point to demographic equilibrium in the Continent region (Table 3). Additionally, mitochondrial statistical parsimony analysis shows a star-shaped phylogeny (Slatkin and Hudson 1991) within the Island region and a large number of rare haplotypes separated by single-nucleotide differences. Finally, recovering population sizes in the islands are concordant with the DIYABC derived estimates of population sizes detailed below.

Table 3 Evidence for changes in population size using microsatellite (Mic) and mitochondrial sequence markers (Seq): $\mathrm{M}$ ratios (Mic), Tajima's D, Fu and Li's F statistic (Seq) calculated for all localities in each region (IS and CO), localities in the Agricultural Zone (AZ), National Park (NP), South Manabí (SMB), Central Manabí (CMB) and North Manabí (NMB)

\begin{tabular}{llll}
\hline Group & M & Tajima's D & F\&L's F \\
\hline IS all loc & $0.4141^{*}$ & $-2.7589^{* * *}$ & $-3.1682^{* *}$ \\
AZ & $0.4112^{\mathrm{NS}}$ & $-2.0511^{*}$ & $-3.6339^{* *}$ \\
NP & $0.4109^{\mathrm{NS}}$ & $-2.6505^{* * *}$ & $-2.7713^{*}$ \\
CO all loc & $0.7248^{\mathrm{NS}}$ & $0.7285^{\mathrm{NS}}$ & $-1.0569^{\mathrm{NS}}$ \\
SMB & $0.6514^{\mathrm{NS}}$ & $0.9894^{\mathrm{NS}}$ & $-1.0569^{\mathrm{NS}}$ \\
CMB & $0.7624^{\mathrm{NS}}$ & $0.2062^{\mathrm{NS}}$ & $-0.0589^{\mathrm{NS}}$ \\
NMB & $0.7534^{\mathrm{NS}}$ & $0.8308^{\mathrm{NS}}$ & $0.8308^{\mathrm{NS}}$ \\
\hline
\end{tabular}

M values for Island groups are from Mok et al. (2014). Asterisks indicate where the $\mathrm{M}$ ratio is significantly lower than values expected under mutation-drift equilibrium and where Tajima's D and Fu and Li's $\mathrm{F}$ values are negative and significantly smaller than the 5,1 or $0.1 \%$ of the tail of simulated values

\section{Contrasting patterns of genetic structure between source and introduced regions}

Hierarchical analyses of molecular variance for all combined microsatellite genotypes as well as, in a parallel analysis, all mitochondrial sequences, revealed significant $\Phi_{\mathrm{CT}}$ indexes for the effect of geographic origin (Continent vs. Island) on the partitioning of genetic variation (Table 4). The percentages of the variation found between localities within each region, $\Phi_{\mathrm{SC}}$, and among all localities, $\Phi_{\mathrm{ST}}$, are also significant for both datasets. However, one notable difference between the two datasets is that the percentage of variation found within localities in mitochondrial sequences is much lower than for microsatellite markers (Micro 70.2\%, Mito 9.82\%).

To compare the patterns of genetic structure among localities in the introduced region with those on the continent, the same analyses were conducted for each region's dataset, where a contrasting pattern emerged. Even though the areas delimited a priori in the continent (SMB, CMB, NMB) and in the Island (AZ, NP) show significant differentiation in the microsatellite dataset (significant $\Phi_{\mathrm{CT}}$ indexes), within-area genetic structuring $\left(\Phi_{\mathrm{SC}}\right)$ is significant on the Continent but not significant on Santa Cruz with either marker, suggesting a higher degree of differentiation among localities within areas (both datasets) and among areas (microsatellites) in the Continent. Despite the significant $\Phi_{\mathrm{ST}}$ indexes in both regions, the proportion of the variation between localities is larger in the Continent than in the introduced range, approximately $20 \%$ less of the genetic variation for either marker is found among island localities (Table 4).

Genetic differentiation between pairs of populations reveal similarly contrasting patterns between Continent and Island regions for both markers: pairwise $\mathrm{F}_{\mathrm{ST}}$ values are larger in magnitude $(\mathrm{p}<0.01)$ and a larger percentage are significant between localities in the Continent: $28 \%$ (CO) versus $2 \%$ (IS) for microsatellite variation and $57 \%$ (CO) versus $28 \%$ (IS) for mitochondrial sequence variation (Fig. 4). These results reinforce the ideas of the patterns determined by the AMOVA analysis with more structured populations in the continent and more homogeneously distributed variation in the introduced range.

StRUCtuRe results obtained using the microsatellite data do not reveal any significant admixture for the introduced populations, nor they point to any one of the continental areas as a clear source of island multilocus genotypes. In every analysis, the number of clusters selected through the Evanno method was $\mathrm{K}=2$, and StRUCTURE recovered our sampling scheme by unambiguously assigning all island and continental individuals to 
Table 4 Analysis of molecular variance

\begin{tabular}{|c|c|c|c|c|c|}
\hline \multirow[t]{2}{*}{ Design } & \multirow[t]{2}{*}{ Source of variation } & \multicolumn{2}{|c|}{ Microsatellite loci } & \multicolumn{2}{|c|}{ Mitochondrial sequences } \\
\hline & & $\%$ & $\mathrm{~F}$ & $\%$ & $\mathrm{~F}$ \\
\hline \multirow[t]{4}{*}{ Continent vs. Island } & Among regions (CO and IS) & 22.81 & $\Theta_{\mathrm{CT}}=0.228^{*}$ & 83.17 & $\Theta_{\mathrm{CT}}=0.832 *$ \\
\hline & Among localities within groups & 6.99 & $\Theta_{\mathrm{SC}}=0.09 *$ & 7 & $\Theta_{\mathrm{SC}}=0.419 *$ \\
\hline & Total among localities & & $\Theta_{\mathrm{ST}}=0.298^{*}$ & & $\Theta_{\mathrm{ST}}=0.901 *$ \\
\hline & Within localities & 70.2 & - & 9.82 & - \\
\hline \multirow[t]{6}{*}{ Continent } & Among areas (SMB, CMB, NMB) & 25.41 & $\Theta_{\mathrm{CT}}=0.254 *$ & 14.73 & $\Theta_{\mathrm{CT}}=0.147(\mathrm{NS})$ \\
\hline & Among localities within areas & 4.39 & $\Theta_{\mathrm{SC}}=0.059(\mathrm{NS})$ & 43.87 & $\Theta_{\mathrm{SC}}=0.515^{*}$ \\
\hline & Total among localities & & $\Theta_{\mathrm{ST}}=0.298 *$ & & $\Theta_{\mathrm{ST}}=0.586^{*}$ \\
\hline & Within localities & 70.2 & - & 41.4 & \\
\hline & Among localities & 20.51 & $\Theta_{\mathrm{ST}}=0.205^{*}$ & 55.27 & $\Theta_{\mathrm{ST}}=0.55^{*}$ \\
\hline & Within localities & 79.49 & - & 44.73 & - \\
\hline \multirow[t]{6}{*}{ Island } & Among areas $(\mathrm{AZ}, \mathrm{NP})$ & 1.96 & $\Theta_{\mathrm{CT}}=0.019 *$ & 9.12 & $\Theta_{\mathrm{CT}}=0.091(\mathrm{NS})$ \\
\hline & Among localities within areas & 1.28 & $\Theta_{\mathrm{SC}}=0.013(\mathrm{NS})$ & 20.17 & $\Theta_{\mathrm{SC}}=0.222(\mathrm{NS})$ \\
\hline & Total among localities & & $\Theta_{\mathrm{ST}}=0.032 *$ & & $\Theta_{\mathrm{ST}}=0.293^{*}$ \\
\hline & Within localities & 96.76 & - & 70.71 & \\
\hline & Among localities & 1.94 & $\Theta_{\mathrm{ST}}=0.019 *$ & 26.33 & $\Theta_{\mathrm{ST}}=0.26^{*}$ \\
\hline & Within localities & 98.06 & - & 73.67 & - \\
\hline
\end{tabular}

Hierarchical distribution of genetic variation among the two main regions (Continent and Island) and areas within each region indicating the percentage of the variation (\%) within and among localities in each grouping and the corresponding fixation indexes for both datasets

$N S$ non significant

$* * \mathrm{p}<0.01, * \mathrm{p}<0.05$
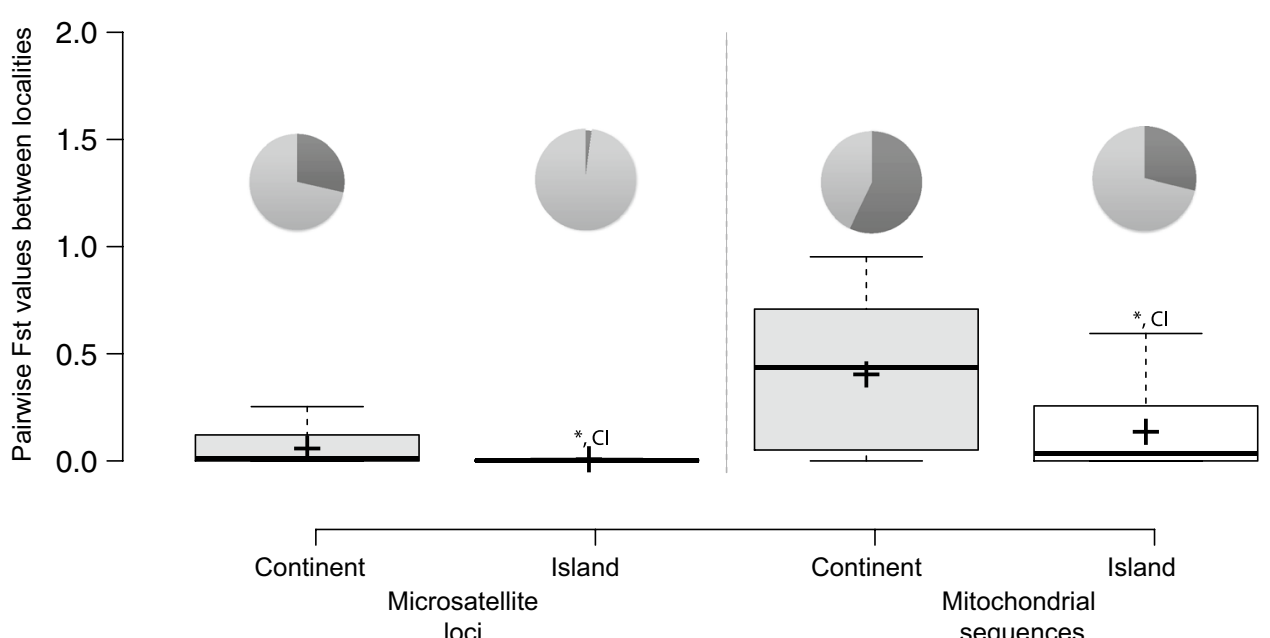

loci

Fig. 4 Comparisons of microsatellite and mitochondrial genetic diversity between localities. Box plots display medians (solid line), means (+) and maximum and minimum values for pairwise $\mathrm{F}_{\mathrm{ST}}$ values across localities within regions. Pie charts indicate proportion of significant (dark gray) and non significant (light gray) pairwse Fst

indexes. Continent (light gray), Santa Cruz Island (white). Codes above the whiskers indicate levels of significance for differences between means $* * p<0.01, * \mathrm{p}<0.05$, CI indicates non-overlapping $95 \%$ confidence intervals between medians

\section{Geographic origin of the introduction} these results suggest that the $G$. h. howdenae populations in Santa Cruz are the result of a single introduction event.
Microsatellite data alone cannot distinguish between the three proposed geographical sources for the introduction using DiYABC. Both analyses using the five or four 
Table 5 Confidence in scenario selection with DiYABC for the introduction history of Galapaganus h. howdenae into Santa Cruz Island in Galápagos

\begin{tabular}{|c|c|c|c|c|c|}
\hline \multirow[t]{2}{*}{ Scenario } & \multirow[t]{2}{*}{ Analysis } & \multirow{2}{*}{$\begin{array}{l}\text { Posterior } \\
\text { probability }\end{array}$} & \multirow[t]{2}{*}{$95 \% \mathrm{CI}$} & \multicolumn{2}{|c|}{ Error type I } \\
\hline & & & & Direct & Logistic \\
\hline \multicolumn{6}{|l|}{ Single source one bottleneck } \\
\hline From NMB and island divergence, timing AZ (b), then NP (v1) & $\mathrm{Mv}$ & 0.0495 & {$[0.0361,0.0630]$} & 0.7 & 0.7 \\
\hline From NMB (vi1) & Miv & 0.1569 & {$[0.1344,0.1795]$} & 0.35 & 0.2 \\
\hline (v1) & $\mathrm{Cv}$ & 0.1832 & {$[0.1661,0.2003]$} & 0.25 & 0.17 \\
\hline (iv1) & Civ & 0.6632 & {$[0.6859,0.6405]$} & 0.03 & 0.02 \\
\hline From NMB and island divergence, timing NP (b), then AZ (v2) & $\mathrm{Mv}$ & 0.0489 & {$[0.0355,0.0622]$} & 0.79 & 0.64 \\
\hline (v2) & $\mathrm{Cv}$ & 0.0625 & {$[0.0475,0.0775]$} & 0.36 & 0.22 \\
\hline From SMB and island divergence, timing AZ (b), then NP (v3) & $\mathrm{Mv}$ & 0.0581 & {$[0.0436,0.0726]$} & 0.41 & 0.46 \\
\hline From SMB (iv2) & Miv & 0.2075 & {$[0.1824,0.2327]$} & 0.22 & 0.17 \\
\hline (v3) & $\mathrm{Cv}$ & 0.054 & {$[0.0400,0.0680]$} & 0.46 & 0.29 \\
\hline (iv2) & Civ & 0.0829 & {$[0.0589,0.1068]$} & 0.26 & 0.23 \\
\hline From SMB and island divergence, timing NP (b), then AZ (v4) & $\mathrm{Mv}$ & 0.0584 & {$[0.0438,0.0729]$} & 0.68 & 0.63 \\
\hline (v4) & $\mathrm{Cv}$ & 0.0553 & {$[0.0411,0.0695]$} & 0.51 & 0.31 \\
\hline From $\mathrm{CMB}$ and island divergence, timing $\mathrm{AZ}$ (b), then NP (v5) & $\mathrm{Mv}$ & 0.0508 & {$[0.0372,0.0644]$} & 0.62 & 0.62 \\
\hline From CMB (iv3) & Miv & 0.1621 & {$[0.1393,0.1850]$} & 0.4 & 0.31 \\
\hline (v5) & $\mathrm{Cv}$ & 0.053 & {$[0.0391,0.0669]$} & 0.33 & 0.22 \\
\hline (iv3) & Civ & 0.0683 & {$[0.0451,0.0915]$} & 0.29 & 0.13 \\
\hline From $\mathrm{CMB}$ and island divergence, timing NP (b), then $\mathrm{AZ}$ (v6) & $\mathrm{Mv}$ & 0.0507 & {$[0.0371,0.0643]$} & 0.73 & 0.65 \\
\hline (v6) & $\mathrm{Cv}$ & 0.0542 & {$[0.0402,0.0682]$} & 0.25 & 0.17 \\
\hline \multicolumn{6}{|l|}{ Single source two (v) or one (vi) botleneck } \\
\hline From ancestral source, timing AZ (b) = NP (b) (v7) & $M v$ & 0.0673 & {$[0.0518,0.0829]$} & 0.29 & 0.19 \\
\hline From ancestral source (vi4) & Miv & 0.2625 & {$[0.2353,0.2898]$} & 0.35 & 0.27 \\
\hline$(\mathrm{v} 7)$ & $\mathrm{Cv}$ & 0.0533 & {$[0.0394,0.0673]$} & 0.4 & 0.27 \\
\hline (iv4) & Civ & 0.172 & {$[0.1486,0.1953]$} & 0.16 & 0.06 \\
\hline $\begin{array}{l}\text { From undifferentiated source, timing } \mathrm{SMB}=\mathrm{CMB}=\mathrm{NMB}, \mathrm{AZ} \\
(\mathrm{b})=\mathrm{NP}(\mathrm{b})(\mathrm{v} 8)\end{array}$ & $\mathrm{Mv}$ & 0.0576 & {$[0.0432,0.0721]$} & 0.6 & 0.63 \\
\hline From undifferentiated source (iv5) & Miv & 0.2108 & {$[0.1856,0.2361]$} & 0.41 & 0.44 \\
\hline (v8) & $\mathrm{Cv}$ & 0.052 & {$[0.0382,0.0657]$} & 0.21 & 0.19 \\
\hline (vi5) & Civ & 0.0136 & {$[0.0132,0.0390]$} & 0.29 & 0.1 \\
\hline \multicolumn{6}{|l|}{ Single source two serial botlenecks } \\
\hline From NMB, timing AZ (b), then NP (b) (v9) & Mv & 0.042 & {$[0.0295,0.0544]$} & 1 & 0.88 \\
\hline (v9) & $\mathrm{Cv}$ & 0.0462 & {$[0.0332,0.0592]$} & 0.56 & 0.49 \\
\hline From NMB, timing NP (b), then AZ (b) (v10) & Mv & 0.0419 & {$[0.0295,0.0544]$} & 0.92 & 1 \\
\hline$(\mathrm{v} 10)$ & $\mathrm{Cv}$ & 0.0457 & {$[0.0328,0.0587]$} & 0.79 & 0.32 \\
\hline From SMB, timing AZ (b), then NP (b) (v11) & Mv & 0.0465 & {$[0.0334,0.0595]$} & 0.75 & 0.75 \\
\hline$(\mathrm{v} 11)$ & $\mathrm{Cv}$ & 0.049 & {$[0.0356,0.0623]$} & 0.72 & 0.63 \\
\hline From SMB, timing NP (b), then AZ (b) (v12) & $\mathrm{Mv}$ & 0.0458 & {$[0.0329,0.0588]$} & 0.79 & 0.67 \\
\hline (v12) & $\mathrm{Cv}$ & 0.0494 & {$[0.0360,0.0629]$} & 0.59 & 0.48 \\
\hline From CMB, timing AZ (b), then NP (b) (v13) & $\mathrm{Mv}$ & 0.0552 & {$[0.0411,0.0694]$} & 0.54 & 0.46 \\
\hline$(\mathrm{v} 13)$ & $\mathrm{Cv}$ & 0.0518 & {$[0.0381,0.0656]$} & 0.55 & 0.64 \\
\hline From CMB, timing NP (b), then AZ (b) (v14) & $\mathrm{Mv}$ & 0.056 & {$[0.0417,0.0702]$} & 0.74 & 0.59 \\
\hline (v14) & $\mathrm{Cv}$ & 0.0528 & {$[0.0389,0.0666]$} & 0.61 & 0.53 \\
\hline \multicolumn{6}{|l|}{ Two separate sources, two bottlenecks } \\
\hline AZ (b) from NMB, NP (b) from SMB (v15) & Mv & 0.046 & {$[0.0330,0.0590]$} & 0.3 & 0.19 \\
\hline$(\mathrm{v} 15)$ & $\mathrm{Cv}$ & 0.0401 & {$[0.0280,0.0523]$} & 0.55 & 0.35 \\
\hline NP (b) from NMB, AZ (b) from SMB (v16) & $\mathrm{Mv}$ & 0.0463 & {$[0.0332,0.0593]$} & 0.48 & 0.26 \\
\hline$(\mathrm{v} 16)$ & $\mathrm{Cv}$ & 0.0304 & {$[0.0282,0.0526]$} & 0.45 & 0.33 \\
\hline $\mathrm{AZ}(\mathrm{b})$ from SMB, NP (b) from CMB (v17) & Mv & 0.0473 & {$[0.0341,0.0604]$} & 0.2 & 0.27 \\
\hline
\end{tabular}


Table 5 (continued)

\begin{tabular}{|c|c|c|c|c|c|}
\hline \multirow[t]{2}{*}{ Scenario } & \multirow[t]{2}{*}{ Analysis } & \multirow{2}{*}{$\begin{array}{l}\text { Posterior } \\
\text { probability }\end{array}$} & \multirow[t]{2}{*}{$95 \% \mathrm{CI}$} & \multicolumn{2}{|c|}{ Error type I } \\
\hline & & & & Direct & Logistic \\
\hline (v17) & $\mathrm{Cv}$ & 0.0101 & {$[0.0079,0.0422]$} & 0.25 & 0.17 \\
\hline $\mathrm{NP}(\mathrm{b})$ from SMB, AZ (b) from CMB (v18) & $\mathrm{Mv}$ & 0.0448 & {$[0.0320,0.0576]$} & 0.46 & 0.29 \\
\hline$(\mathrm{v} 18)$ & $\mathrm{Cv}$ & 0.0179 & {$[0.0160,0.0397]$} & 0.36 & 0.17 \\
\hline $\mathrm{AZ}(\mathrm{b})$ from NMB, NP (b) from CMB (v19) & $\mathrm{Mv}$ & 0.0432 & {$[0.0306,0.0558]$} & 0.36 & 0.5 \\
\hline$(\mathrm{v} 19)$ & $\mathrm{Cv}$ & 0.0199 & {$[0.0200,0.0520]$} & 0.41 & 0.19 \\
\hline NP (b) from NMB, AZ (b) from CMB (v20) & $\mathrm{Mv}$ & 0.0438 & {$[0.0311,0.0565]$} & 0.88 & 0.63 \\
\hline$(\mathrm{v} 20)$ & $\mathrm{Cv}$ & 0.0194 & {$[0.0203,0.0515]$} & 0.24 & 0.16 \\
\hline
\end{tabular}

Italics correspond to values associated to the two selected scenarios

(b) After an island population code indicates a proposed bottleneck. Analysis codes correspond to dataset (microsatellite, M, or combined microsatellite and mitochondrial sequences, C) and population arrangement [two or one island populations for a total of 5 (v) or 4 (iv)]

population arrangement ( $\mathrm{Mv}$ and Miv) result in higher posterior probabilities for a scenario where the island population/s originated from a single ancestral source, independent of the three sampled continental areas (Scenario v7/iv4). This scenario was followed closely in posterior probability by a scenario proposing two simultaneous introductions from an undifferentiated source (Scenario v8/ iv5) (Online Resource 4). However, in these two analyses, the most likely scenario showed relatively high error rates (Table 5), suggesting that it could not be clearly distinguished from other scenarios. In summary, microsatellite multi-locus genotypes do not convey a clear geographic signal and could indicate that either the signal has been obscured by the rapid origin of new microsatellite alleles during a post-introduction expansion, or that the geographic source of the introduction of $G$. h. howdenae lies beyond the continental range currently sampled. However, the failure of the scenarios containing ghost populations to be preferred under any analysis (data not shown) appears to reject the latter explanation.

When analyzing the combined dataset under the five or four population arrangement (Civ and $\mathrm{Cv}$ ) there was a clear geographic signal. The scenario chosen pointed towards Northern Manabí as the source of the introduction with a larger posterior probability compared to all other proposed scenarios (Online resource 4 and Fig. 5). Scenarios v1 and iv1 both result in the largest posterior probability; scenario v1 proposes an introduction from Northern Manabí into the Agricultural Zone with subsequent differentiation into the National Park, while scenario iv1 proposes one introduction into the islands. Additionally, the error associated with scenario choice is much smaller for the analysis using the four-population arrangement (Civ) (Table 5). The addition of mitochondrial sequences to the microsatellite dataset allows more effective differentiation among scenarios and favors the Northern Manabí area, as the most likely source of the introduction.
Some of the population parameters estimated for scenario vil with the combined dataset resulted in posterior distributions with clear peaks and low bias indices providing robust estimations. The modes of the number of founding individuals $\left(\mathrm{N}_{4 \mathrm{f}}\right)$ was estimated as 12.44 (95\% HPD $7.65-43.22$, mmrb $=0.281$ ), the current size of the introduced population $\left(\mathrm{N}_{4}\right)$ as 1642 (95\% HPD 1590-1767, mmrb $=0.209$ ), the timing of the population bottleneck $\left(t_{1}\right)$ as $101(95 \%$ HPD $49.5-122, \mathrm{mmrb}=0.3263)$, and the population size of two of the continental areas $\left(\mathrm{N}_{1}\right) 3690$ (95\% HPD 3060-4560, mmrb=0.1937) and $\left(\mathrm{N}_{2}\right) 5110$ (95\% HPD 2590-9120, mmrb=0.079). Other population parameters such as the current population size in Northern Manabí $\left(\mathrm{N}_{3}\right)$ and the time of divergence between the continental areas could not be reliably estimated given the lack of clear peaks and large associated bias.

The statistical parsimony haplotype network among the island haplotypes showed a shallow structure lacking apparent phylogeographic structure, with a star-shaped topology and in general only a few mutation steps among haplotypes. Most of the island haplotypes are present only once (UH), the most frequent island haplotype (IS16) is equally represented in both areas of Santa Cruz Island and one haplotype is common to both island areas (Fig. 6). One of the more divergent National Park's haplotypes (UH34) provides the connection to the continental haplotypes. The two regions (IS and CO) do not share any haplotypes; however, there are continental haplotypes that span two continental areas $(\mathrm{CSH} 1,4)$ and some that are locally shared (LSH 7, 12). The structure of the network among the continental haplotypes is more complex, with some geographic structure separating four out of the five haplotypes from Northern Manabí. The contrasting structure between the Island and Continent networks is in agreement with the Amova mitochondrial results, and the network haplotype connections between the two regions supports the introduction scenario chosen by DIYABC using the combined dataset. 


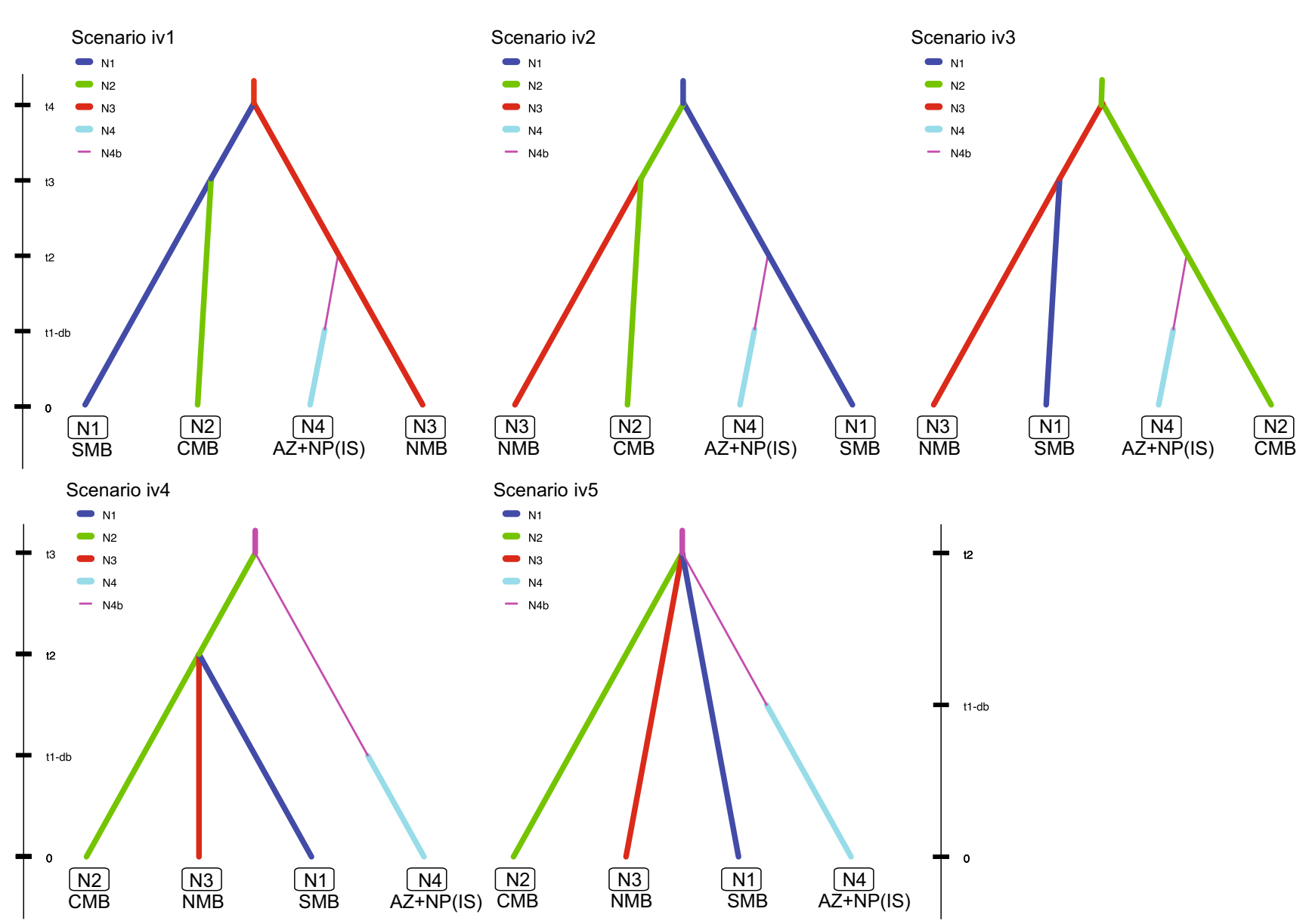

Fig. 5 Graphs representing the five proposed scenarios for $G . h$. howdenae examined with DIYABC for Miv and Civ analyses. In each scenario thin lines indicate reductions in population sizes (bottle- necks) after an introduction event. $\mathrm{N}_{4 \mathrm{f}}$ represents the effective number of founding individuals and $\mathrm{N}_{1-4}$ represent the current population sizes of the three continental areas and the island population

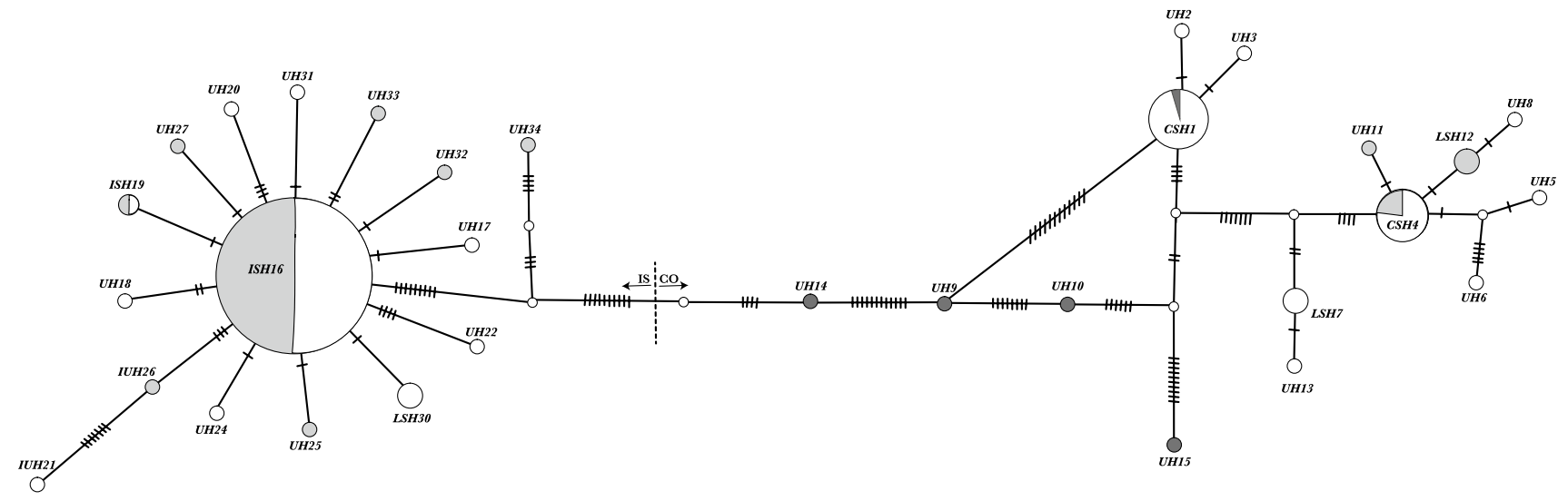

Fig. 6 Mitochondrial haplotype network for G. $h$.howdenae, obtained using the PopArt software implementing the TCS algorithm. The area of the circles is approximately proportional to haplotype frequency. Dashed vertical line on the network structure depicts the separation between Island (IS) and Continental (CO) haplotypes. Color indicates area within each region where the haplotypes are found.
Island areas are white Agricultural Zone; light gray National Park. Continental areas are white South Manabí, light gray Central Manabí, dark gray North Manabí. Haplotype labels follow Fig. 1: CSH continental shared haplotype, ISH island shared haplotype, $L S H$ locally shared haplotype and UH denotes a unique haplotype 


\section{Discussion}

\section{Recovery through demographic expansion after a single introduction pulse in Santa Cruz}

Invasion is now typically conceptualized as a multistage process that entails a lag phase, during which adaptations that facilitate invasiveness arise, followed by rapid range expansion (Keller and Taylor 2008). In our study, we capture two snapshots of this multistage process by using two markers: mitochondrial sequences, which retain signals of the introduction history into the islands, and microsatellites, which reflect the standing variation in island populations after establishment and expansion.

Mitochondrial estimates of genetic diversity in mussel populations have been found to be significantly higher in invasive populations than in native ones, and studies point to multiple introductions as the source of that diversity (Gillis et al. 2009). Similarly, increased mitochondrial sequence variation within introduced anole populations in Florida and the Dominican Republic has been ascribed to the influx from multiple differentiated native populations (Kolbe et al. 2004, 2007, 2008). Multiple introduction pulses have also been argued as facilitating establishment (Therriault et al. 2005) and promoting expansions of introduced populations' geographical ranges (Simon-Bouhet et al. 2006; Tsuchida et al. 2014), life history strategies (Facon et al. 2008), and host ranges (Peccoud et al. 2008). However, multiple introductions not always compensate for the depleting effects of introduction bottlenecks on genetic diversity (Lindholm et al. 2005). Our study reveals lower mitochondrial but improved microsatellite within-population diversity in the introduced range for $G$. h. howdenae. Multiple introduction pulses from either a single source, or from differentiated sources, do not fit the patterns that we find for this species. Our previous microsatellite study focusing on island populations failed to find genetically distinct clusters within the introduced range and rejected the notion of multiple introductions (Mok et al. 2014). In agreement, all the preferred introduction scenarios selected through DIYABC using our current expanded dataset (in either the microsatellite: Miv and Mv, or the combined analyses: $\mathrm{Civ}$ and $\mathrm{Cv}$ ) feature a single introduction event. Similarly, other successful insect introductions and range expansions have not relied on admixture from multiple introductions (Wu et al. 2015). At this time, we propose that all island $G$. h. howdenae have originated from a single introduction pulse.

Our results also suggest that $G . h$. howdenae populations in Santa Cruz have recovered from recent bottlenecks. Assessments of allele distributions ( $M$-ratio) and likelihood based estimators both provided evidence of a past population decline in Santa Cruz (Mok et al. 2014). The view that these island populations are now recovered from founder effects is supported by the differences between bottleneck $\left(\mathrm{N}_{4 \mathrm{f}}\right)$ and current $\left(\mathrm{N}_{4}\right)$ population size parameters estimated using the preferred scenarios in DIYABC. In addition to the recovery in population numbers, the recovery in introduced microsatellite genetic diversity is evidenced by our comparisons with estimates from continental populations. Furthermore, indexes computed on the mitochondrial dataset, such as Tajima's D and Fu and Li's F, indicate a significant negative deviation from evolutionary neutrality in the island populations. These statistics, in combination with the star shaped haplotype network, are indicative of a deviation from equilibrium, likely caused by a post-introduction population expansion. Population and range expansions in other island introduced species have been linked to invasion success (Curry et al. 2016). However, the relevance of the average amount of standing genetic diversity to the maintenance of populations of successful invaders has been called into question in genomic studies, which instead favor the importance of preservation of polymorphism in specific genes (Vera et al. 2016), species-specific life-history traits, or the phylogeographic history in the native source range (Trucchi et al. 2016).

\section{Homogeneous population genetic structure in the introduced range: recent origin and rapid population expansion}

Lack of genetic structure across introduced ranges can be found in non-native groups with very different dispersal abilities, such as Australian cats (Spencer et al. 2016), European raccoon dogs (Drygala et al. 2016) and Hawaiian melon flies (Prabhakar et al. 2012). In many cases such homogeneous distribution of the existing genetic variants can be explained by the occurrence of rapid population expansions. Interestingly, not all proposed recent introductions and population expansions result in non-significant spatial structuring, such as for introduced Aedes aegypti mosquitos on Java island (Rasic et al. 2015). However, the spatial genetic structure detected in the mosquito study is suggested to be under stronger influence of human-assisted gene flow than active mosquito movement.

Island populations of $G . h$. howdenae are in general less genetically structured than their continental counterparts; this is evidenced by all island multi-locus microsatellite genotypes being assigned to the same genetic cluster by STRUCTURE, by both markers displaying a lower proportion of significant island pairwise $\mathrm{F}_{\mathrm{ST}}$ values, and by non-significant values of differentiation between localities within island areas $\left(\Phi_{\mathrm{SC}}\right)$, in contrast to significant values within areas in the continent. When first detecting the genetic homogeneity of mitochondrial variants across introduced populations, we highlighted the 
differences in dispersal abilities between $G$. h. howdenae and its flightless endemic congeners that display highly structured populations (Sequeira et al. 2012). However, the contrasting genetic structure between continental and introduced populations of $G$. h. howdenae found in this study cannot be due to differing vagility, given that populations from both regions harbor individuals with equally developed wings (Lanteri 2004). In this case, the contrasting genetic structure can be explained by a combination of the disparities in the persistence and demographic history of the populations in the two regions. Likelihood-based (Mok et al. 2014) as well as DıYABCderived estimates of the timing of the introduction of $G$. $h$. howdenae into the islands, place the introduction event at about 100 years ago, within the colonization period (1832-1959) (González et al. 2008). Even though this estimate predates the first collection record by several decades (Lanteri 2004), and labels G. h. howdenae as an older, less concerning introduction (Causton et al. 2006), it still underscores the fact that island populations are younger and more recently established than those in the continent. Continental Naupactini have persisted at least since the Mid Pliocene (Sequeira et al. 2008a; del Rio et al. 2015), and presumably accumulated more neutral variation across space and time. In sum, we propose that the genetic homogeneity and lack of spatial structure across the localities in the introduced range could be the signature of recently established populations of mobile weevils undergoing demographic expansions.

A compounding factor for the contrasting genetic structures across regions, even within areas of comparable size, could be the prevalence of suitable host plants in close proximity in the Agricultural Zone, most of those also non-native to the islands, in contrast to the more patchy distribution of the single preferred host plants in the source range (Quijano-Abril et al. 2006). An additional factor to consider could be the paucity of potential natural enemies and competitors for the naturalized island populations, in contrast to those faced by the longer-established populations in the continental range. However, the generalist feeding preferences exhibited by island $G$. h. howdenae, and the lack of ecological data on this species makes it hard to point to any one of these disparities as the main factor contributing to the lack of spatial structure in the introduced range. Regardless of the underlying causes, the maintenance of connectivity across the area of introduction could ensure that less frequent allelic variants, either arriving or arising at the edges of the introduced range, spread throughout the area of introduction (Mok et al. 2014), further contributing to the genetic variation within each locality.

\section{Weevils as stowaways on plant material can explain the Northern Manabí ancestry of Santa Cruz populations}

Because the reconstruction of invasion routes is required for defining and testing hypotheses concerning the environmental and evolutionary factors responsible for biological invasions, it has been proposed as facilitating the design of strategies for controlling or preventing invasions (Estoup and Guillemaud 2010). Approximate Bayesian computation has been previously implemented to understand introduction history in continental areas (Miller et al. 2005; Kim et al. 2016; Wood et al. 2016) as well as into islands such as New Zealand (Lye et al. 2011; Purcell et al. 2012) and the Galápagos (Caetano et al. 2012). Using simulated datasets the $\mathrm{ABC}$ based method was found to give correct inferences and to be more efficient for inferring introduction routes of invasive species than methods based on raw values of statistics (Guillemaud et al. 2010). The powerful DIYABC platform allows the comparison of complex scenarios involving bottlenecks, serial or independent introductions and genetic admixture (Gaubert et al. 2015) and has allowed the exploration of the role of multiple introductions (Miller et al. 2005; Dutech et al. 2012), debunked ideas of recent introductions in favor of older ones (Zhang et al. 2012), revealed complex patterns of introduction (Simon et al. 2011; Gaubert et al. 2015), and highlighted cases of widespread secondary invasions (Lombaert et al. 2010).

The two markers used in this study differ in their utility to reconstruct the invasion history of $G$. h. howdenae into Santa Cruz: microsatellite markers alone do not distinguish between proposed scenarios with the desired degree of accuracy, nor do they suggest any of the three continental areas as potential sources, possibly due to the wealth of new island-specific alleles that we propose have evolved after the introduction during a subsequent population expansion. On the other hand, a combined dataset including mitochondrial sequences more accurately selects a scenario proposing Northern Manabí as the continental source for all island $G$. h. howdenae. Mitochondrial sequences appear to have retained more of the signature of the recent introduction history of $G$. h. howdenae, as seen in other recent island introductions (Nicolas et al. 2015).

The selection of Northern Manabí as the continental source is surprising, given that other sampled areas are closer to the port of Guayaquil where most commercial and passenger transport to the islands originates. However, this scenario is in agreement with the pattern derived from the haplotype network, where haplotypes from Northern Manabí and the National Park area in Santa Cruz are connected. Given the location of the main ports of entry for goods in Puerto Ayora, we have argued that a likely mode 
of introduction of $G$. h. howdenae into Santa Cruz was together with imported plants, first into lowland areas of the island and later, either passively transported with those plants, or actively dispersed into the Agricultural Zone where it established populations (Mok et al. 2014). If we consider that the likely modes of transport into the islands for these plant-dependent weevils are with imported plants or construction materials (Peck et al. 1998; Causton et al. 2006; Peck 2006), then it would be equally likely that the island-bound plants could have originated in highland areas, further away from the port of Guayaquil, and transported there with human aid, harboring $G$. h. howdenae larvae or adults. Even though the transport of weevils into the islands was human-mediated, identifying the geographical origin of the introduction as a higher elevation habitat could provide clues about the environmental background of the founders and shed light on the reasons behind the environmental amplitude displayed by the now naturalized populations. However, given the large amount of microsatellite variation found in island populations, and that a large percentage is due to new island alleles, and if we assume that some of the newly acquired neutral variation can be accompanied by selectively advantageous changes, then the answer to the question "where can introduced populations learn their tricks?" could be: right at their new location.

\section{Conclusions}

We conclude that the genetic diversity of recently introduced populations does not necessarily rely on multiple introduction pulses, but can augment through demographic processes such as population expansion. Additionally, we propose a highland origin for the introduction and point to the environmental background of the original founders. These findings highlight that, as expected, in situ processes and aspects of the introduction history can be underlying the introduced population's chances of establishment and naturalization. Nevertheless, we suggest that the monitoring of older, now naturalized, introduced insects remains relevant given their ability to expand their ranges, acquire and damage new endemic plant hosts, and potentially displace threatened endemic congeners.

Acknowledgements We gratefully acknowledge the logistical support of Dr. L. Albuja (Escuela Politécnica Nacional) and O. Suing (Universidad Central del Ecuador). We also greatly benefited from the support of personnel at Parque Nacional Machalilla, Bosque Protector Cerro Blanco, Reserva Jama Coaque, Finca Monoloco and Reserva Manglares Churute. Field assistance was provided by M. Koniger; J., M. and A. Rosado and D. Quinde. M. K. Dornon and A. Hakes provided laboratory assistance. Scientific research permits for the Galápagos collecting trips were obtained from the Parque Nacional Galápagos through the Charles Darwin Research Station. Continental, province-based research and export permits were obtained from the Ministerio Del Ambiente (Manabí, No: 006-AT-DPAM-MAE). This work was supported by the National Science Foundation (Award Number 0817978 to A. S. S.); Brachman Hofmann Funds from Wellesley College (to A. S. S) and a Fulbright Scholar award to A. S. S.

\section{References}

Abedrabbo S (1991) Nueva Avispa introducida en las Islas. Carta Inform 31:4

Abedrabbo S, Kathirithamby J, Olmi M (1991) Contribution to the knowledge of the Elenchidae, Strepsiptera and Dryinidae, Hymenoptera, Chrysidoidea of the Galápagos islands. Boll Ist Entomol Univ Stud Bologna 45:121-128

Allendorf F, Lundquist L (2003) Introduction: population biology, evolution, and control of invasive species. Conserv Biol 17:24-30

Alvarez CC, Causton CE, Hoddle MS, Hoddle CD, van Driesche R, Stanek EJ (2012) Monitoring the effects of Rodolia cardinalis on Icerya purchasi populations on the Galápagos Islands. Biocontrol 57:167-179

Berenbaum MR, Zangerl AR (1991) Acquisition of a native host plant by an introduced oligophagous herbivore. Oikos 62:153-159

Boada R (2005) Insects associated with endangered plants in the Galápagos Islands, Ecuador. Entomotropica 20:77-88

Caetano S, Currat M, Pennington RT, Prado D, Excoffier L, Naciri Y (2012) Recent colonization of the Galápagos by the tree Geoffroea spinosa Jacq. (Leguminosae). Mol Ecol 21:2743-2760

Causton CE, Lincango MP, Poulsom TGA (2004) Feeding range studies of Rodolia cardinalis (Mulsant), a candidate biological control agent of Icerya purchasi Maskell in the Galápagos islands. Biol Control 29:315-325

Causton CE, Sevilla CR, Porter SD (2005) Eradication of the little fire ant, Wasmannia auropunctata (Hymenoptera: Formicidae), from Marchena Island, Galápagos: on the edge of success? Fla Entomol 88:159-168

Causton CE, Peck SB, Sinclair BJ, Roque-Albelo L, Hodgson CJ, Landry B (2006) Alien insects: threats and implications for conservation of Galápagos Islands. Ann Entomol Soc Am 99:121-143

Chambers JM, Cleveland WS, Kleiner B, Tukey PA (1983) Graphical methods for data analysis. Wadsworth, Belmont

Chenna R, Sugawara H, Koike T, Lopez R, Gibson TJ, Higgins DG, Thompson JD (2003) Multiple sequence alignment with the Clustal series of programs. Nucleic Acids Res 31:3497-3500

Clement M, Posada DCKA, Crandall KA (2000) TCS: a computer program to estimate gene genealogies. Mol Ecol 9(10):1657-1659

Cockerham C, Weir B (1984) Estimating F-statistics for the analysis of population structure. Evol Int J Org Evol 38:1358-1370

Cockerham C, Weir B (1987) Correlations, descent measures: drift with migration and mutation. Proc Natl Acad Sci USA 84:8512-8514

Colautti RI, Manca M, Viljanen M, Ketelaars HAM, Burgi H, Macisaac HJ, Heath DD (2005) Invasion genetics of the Eurasian spiny waterflea: evidence for bottlenecks and gene flow using microsatellites. Mol Ecol 14:1869-1879

Cole NC, Jones CG, Harris S (2005) The need for enemy-free space: the impact of an invasive gecko on island endemics. Biol Conserv 125:467-474

Cornuet JM, Pudlo P, Veyssier J, Dehne-Garcia A, Gautier M, Leblois R, Marin JM, Estoup A (2014) DIYABC v2.0: a software to make approximate Bayesian computation inferences about 
population history using single nucleotide polymorphism, DNA sequence and microsatellite data. Bioinformatics 30:1187-1189

Curry PA, Yeung NW, Hayes KA, Meyer WM, Taylor AD, Cowie RH (2016) Rapid range expansion of an invasive predatory snail, Oxychilus alliarius (Miller 1822), and its impact on endemic Hawaiian land snails. Biol Invasions 18:1769-1780

del Rio MG, Morrone JJ, Lanteri AA (2015) Evolutionary biogeography of South American weevils of the tribe Naupactini (Coleoptera: Curculionidae). J Biogeogr 42:1293-1304

Drygala F, Korablev N, Ansorge H, Fickel J, Isomursu M, Elmeros M, Kowalczyk R, Baltrunaite L, Balciauskas L, Saarma U, Schulze C, Borkenhagen P, Frantz AC (2016) Homogenous Population Genetic Structure of the Non-Native Raccoon Dog (Nyctereutes procyonoides) in Europe as a Result of Rapid Population Expansion. PLoS ONE 11:e0153098

Dutech C, Barres B, Bridier J, Robin C, Milgroom MG, Ravigne V (2012) The chestnut blight fungus world tour: successive introduction events from diverse origins in an invasive plant fungal pathogen. Mol Ecol 21:3931-3946

Earl DA, Vonholdt BM (2012) STRUCTURE HARVESTER: a website and program for visualizing STRUCTURE output and implementing the Evanno method. Conserv Genet Resour 4:359-361

Edgington HA, Ingram CM, Taylor DR (2016) Cyto-nuclear discordance suggests complex evolutionary history in the cave-dwelling salamander, Eurycea lucifuga. Ecol Evol 6(17):6121-6128

Emerson BC, Kolm N (2005) Species diversity can drive speciation. Nature 434:1015-1017

Estoup A, Guillemaud T (2010) Reconstructing routes of invasion using genetic data: why, how and so what? Mol Ecol 19:4113-4130

Estoup A, Jarne P, Cornuet J-M (2002) Homoplasy and mutation model at microsatellite loci and their consequences for population genetics analysis. Mol Ecol 11:1591-1604. doi:10.1046/j.1365-294X.2002.01576.x

Evanno G, Regnaut S, Goudet J (2005) Detecting the number of clusters of individuals using the software STRUCTURE: a simulation study. Mol Ecol 14:2611-2620

Evans EW (2004) Habitat displacement of North American ladybirds by an introduced species. Ecology 85:637-647

Excoffier L, Laval G, Schneider S (2005) Arlequin (version 3.0): An integrated software package for population genetics data analysis. Evol Bioinform Online 1:47-50

Facon B, Pointier J-P, Jarne P, Sarda V, David P (2008) High genetic variance in life-history strategies within invasive populations by way of multiple introductions. Curr Biol 18:363-367

Fitzpatrick BM, Shaffer HB (2007) Hybrid vigor between native and introduced salamanders raises new challenges for conservation. Proc Natl Acad Sci USA 104:15793-15798

Flanders J, Jones G, Benda P, Dietz C, Zhang S, Li G, Sharifi M, Rossiter SJ (2009) Phylogeography of the greater horseshoe bat, Rhinolophus ferrumequinum: contrasting results from mitochondrial and microsatellite data. Mol Ecol 18:306-318

$\mathrm{Fu}$ YX, Li WH (1993) Statistical tests of neutrality of mutations. Genetics 133:693-709

Garrett LJH, Jones CG, Cristinacce A, Bell DJ (2007) Competition or co-existence of reintroduced, critically endangered Mauritius fodies and invasive Madagascar fodies in lowland Mauritius? Biol Conserv 140:19-28

Garza JC, Williamson EG (2001) Detection of reduction in population size using data from microsatellite loci. Mol Ecol 10:305-318

Gaubert P, Del Cerro I, Centeno-Cuadros A, Palomares F, Fournier P, Fonseca C, Paillat JP, Godoy JA (2015) Tracing historical introductions in the Mediterranean Basin: the success story of the common genet (Genetta genetta) in Europe. Biol Invasions 17:1897-1913
Gillis NK, Walters LJ, Fernandes FC, Hoffman EA (2009) Higher genetic diversity in introduced than in native populations of the mussel Mytella charruana: evidence of population admixture at introduction sites. Divers Distrib 15:784-795

González JA, Montes C, Rodríguez J, Tapia W (2008) Rethinking the Galapagos Islands as a complex social-ecological system: implications for conservation and management. Ecol Soc 13(2)

Grant PR, Grant BR, Petren K, Keller LF (2005) Extinction behind our backs: the possible fate of one of the Darwin's finch species on Isla Floreana, Galápagos. Biol Conserv 122:499-503

Guillemaud T, Beaumont MA, Ciosi M, Cornuet JM, Estoup A (2010) Inferring introduction routes of invasive species using approximate Bayesian computation on microsatellite data. Heredity 104:88-99

Hoddle MS, Ramirez CC, Hoddle CD, Loayza J, Lincango MP, Van Driesche RG, Causton CE (2013) Post release evaluation of Rodolia cardinalis (Coleoptera: Coccinellidae) for control of Icerya purchasi (Hemiptera: Monophlebidae) in the Galápagos Islands. Biol Control 67:262-274

Hubisz MJ, Falush D, Stephens M, Pritchard JK (2009) Inferring weak population structure with the assistance of sample group information. Mol Ecol Resour 9:1322-1332

Jakobsson M, Rosenberg NA (2007) CLUMPP: a cluster matching and permutation program for dealing with label switching and multimodality in analysis of population structure. Bioinformatics 23:1801-1806

Keller SR, Taylor DR (2008) History, chance and adaptation during biological invasion: separating stochastic phenotypic evolution from response to selection. Ecol Lett 11:852-866

Kim H, Hoelmer KA, Lee S (2016) Approximate bayesian computation reveals the origin of introduction of the soybean aphid in North America. In: Korea Society of Applied Entomology Annual General Meeting and Symposium, pp 110-110

Kolbe JJ, Glor RE, Schettino LRG, Lara AC, Larson A, Losos JB (2004) Genetic variation increases during biological invasion by a Cuban lizard. Nature 431:177-181

Kolbe JJ, Glor RE, Schettino LR, Lara AC, Larson A, Losos JB (2007) Multiple sources, admixture, and genetic variation in introduced Anolis lizard populations. Conserv Biol 21:1612-1625

Kolbe JJ, Larson A, Losos JB, de Queiroz K (2008) Admixture determines genetic diversity and population differentiation in the biological invasion of a lizard species. Biol Lett 4:434-437

Kruskal WH, Wallis WA (1952) Use of ranks in one-criterion variance analysis. J Am Stat Assoc 47:583-621

Lanteri AA (1992) Systematics, Cladistics and Biogeography of a New Weevil Genus, Galapaganus (Coleoptera, Curculionidae) from the Galápagos Islands, and Coasts of Ecuador and Peru. Trans Am Entomol Soc 118:227-267

Lanteri AA (2004) New taxonomic and biogeographic information on Galapaganus femoratus species group (Coleoptera: Entiminae). Trans Am Entomol Soc (Phila) 130:177-192

Lefebvre T, Vargo EL, Zimmermann M, Dupont S, Kutnik M, Bagnères A-G (2016) Subterranean termite phylogeography reveals multiple postglacial colonization events in southwestern Europe. Ecol Evol 6:5987-6004

Leger EA, Espeland EK (2010) Coevolution between native and invasive plant competitors: implications for invasive species management. Evol Appl 3:169-178

Librado P, Rozas J (2009) DnaSP v5: a software for comprehensive analysis of DNA polymorphism data. Bioinformatics 25:1451-1452

Lincango MP, Causton CE, Alvarez CC, Jimenez-Uzcategui G (2011) Evaluating the safety of Rodolia cardinalis to two species of Galapagos finch; Camarhynchus parvulus and Geospiza fuliginosa. Biol Control 56:145-149 
Lindholm AK, Breden F, Alexander HJ, Chan WK, Thakurta SG, Brooks R (2005) Invasion success and genetic diversity of introduced populations of guppies Poecilia reticulata in Australia. Mol Ecol 14:3671-3682

Lombaert E, Guillemaud T, Cornuet JM, Malausa T, Facon B, Estoup A (2010) Bridgehead effect in the worldwide invasion of the biocontrol harlequin ladybird. PLoS ONE 5:e9743

Lye GC, Lepais O, Goulson D (2011) Reconstructing demographic events from population genetic data: the introduction of bumblebees to New Zealand. Mol Ecol 20:2888-2900

Mende MB, Bartel M, Hundsdoerfer AK (2016) A comprehensive phylogeography of the Hyles euphorbiae complex (Lepidoptera: Sphingidae) indicates a 'glacial refuge belt'. Sci Rep 6:29527

Miller N, Estoup A, Toepfer S, Bourguet D, Lapchin L, Derridj S, Kim KS, Reynaud P, Furlan L, Guillemaud T (2005) Multiple transatlantic introductions of the western corn rootworm. Science 310:992-992

Mok HF, Stepien CC, Kaczmarek M, Albelo LR, Sequeira AS (2014) Genetic status and timing of a weevil introduction to Santa Cruz Island, Galápagos. J Hered 105:365-380

Nei M, Maruyama T, Chakraborty R (1975) The bottleneck effect and genetic variability in populations. Evol Int J Org Evol 29:1-10

Nicolas V, Grandcolas P, Braux F, Jourdan H, Malau A, Couloux A, Ohler A (2015) Recent species in old Islands: the origin of introduced populations of Litoria aurea (Anura: Hylidae) in New Caledonia and Wallis. Amphib-Reptilia 36:65-81

Oosterhout C, Hutchinson W, Wills D, Shipley P (2004) MICROCHECKER: software for identifying and correcting genotyping errors in microsatellite data. Mol Ecol Notes 4:535-538

Peccoud J, Figueroa CC, Silva AX, Ramirez CC, Mieuzet L, Bonhomme J, Stoeckel S, Plantegenest M, Simon J-C (2008) Host range expansion of an introduced insect pest through multiple colonizations of specialized clones. Mol Ecol 17:4608-4618

Peck SB (2006) The beetles of the Galápagos Islands, Ecuador: evolution, ecology, and diversity (Insecta: Coleoptera). NRC Research Press, Ottawa

Peck SB, Heraty J, Landry B, Sinclair BJ (1998) Introduced insect fauna of an oceanic archipelago: the Galápagos Islands, Ecuador. Am Entomol 44:218-237

Peery MZ, Gutierrez RJ, Kirby R, Ledee OE, Lahaye W (2012) Climate change and spotted owls: potentially contrasting responses in the Southwestern United States. Glob Change Biol $18: 865-880$

Prabhakar CS, Mehta PK, Sood P, Singh SK, Sharma P, Sharma PN (2012) Population genetic structure of the melon fly, Bactrocera cucurbitae (Coquillett) (Diptera: Tephritidae) based on mitochondrial cytochrome oxidase (COI) gene sequences. Genetica 140:83-91

Pritchard JK, Stephens M, Donnelly P (2000) Inference of population structure using multilocus genotype data. Genetics 155:945-959

Purcell KM, Ling N, Stockwell CA (2012) Evaluation of the introduction history and genetic diversity of a serially introduced fish population in New Zealand. Biol Invasions 14:2057-2065

Quijano-Abril MA, Callejas-Posada R, Miranda-Esquivel DR (2006) Areas of endemism and distribution patterns for Neotropical Piper species (Piperaceae). J Biogeogr 33:1266-1278

Rasic G, Endersby-Harshman N, Tantowijoyo W, Goundar A, White V, Yang Q, Filipovic I, Johnson P, Hoffmann AA, Arguni E (2015) Aedes aegypti has spatially structured and seasonally stable populations in Yogyakarta, Indonesia. Parasit Vectors 8:610

Raymond M, Rousset F (1995) GENEPOP (Version 1 2): population genetics software for exact tests and ecumenicism. J Hered $86: 248-249$
Roque Albelo L, Causton C (1999) El Niño and introduced insects in the Galápagos Islands: different dispersal strategies, similar effects. Not Galapagos 60:30-36

Roque Albelo L, Causton CE, Mieles A (2003) Population decline of Galápagos endemic Lepidoptera on Volcan Alcedo (Isabela island, Galapagos Islands, Ecuador): an effect of the introduction of the cottony cushion scale? Bull Inst R Sci Nat Belg Entomol 73:1-4

Roque Albelo L, Berg M, Galarza M (2006) "Polizontes peligrosos", dispersión de insectos entre las islas Galápagos en barcos de turismo. In: Research report. Charles Darwin Research Station, Puero Ayora, Galapagos

Rosenberg NA (2004) DISTRUCT: a program for the graphical display of population structure. Mol Ecol Notes 4:137-138

Sequeira AS, Lanteri AA, Scataglini MA, Confalonieri VA, Farrell BD (2000) Are flightless Galapaganus weevils older than the Galápagos Islands they inhabit? Heredity 85:20-29

Sequeira AS, Lanteri AA, Roque Albelo L, Bhattacharya S, Sijapati M (2008a) Colonization history, ecological shifts and diversification in the evolution of endemic Galápagos weevils. Mol Ecol 17:1089-1107

Sequeira AS, Sijapati M, Lanteri AA, Roque Albelo L (2008b) Nuclear and mitochondrial sequences confirm complex colonization pattern and clear species boundaries for flightless weevils in the Galápagos archipelago. Philos Trans R Soc Lond B Biol Sci 363:3439-3452

Sequeira AS, Stepien CC, Sijapati M, Roque Albelo L (2012) Comparative genetic structure and demographic history in endemic galapagos weevils. J Hered 103:206-220

Sequeira AS, Stepien CC, Tran CT, Stuckert A, Roque Albelo L, Guo WX (2016) Exploring the legacy of goat grazing: signatures of habitat fragmentation on genetic patterns of endemic weevil populations in Northern Isabela Island, Galapagos (Ecuador). Conserv Genet 17:903-920

Simbana W, Tye A (2009) Reproductive biology and responses to threats and protection measures of the total population of a critically endangered Galapagos plant, Linum cratericola (Linaceae). Bot J Linn Soc 161:89-102

Simberloff DS (1986) Introduced insects: a biogeographic and systematic perspective. In: Mooney HA, Drake JA (eds) Ecology of biological invasions of North America and Hawaii. Springer, Berlin, pp 3-26

Simon A, Britton R, Gozlan R, Oosterhout C, Volckaert FAM, Hanfling B (2011) Invasive cyprinid fish in Europe originate from the single introduction of an admixed source population followed by a complex pattern of spread. PLoS ONE 6:e18560

Simon-Bouhet B, Garcia-Meunier P, Viard F (2006) Multiple introductions promote range expansion of the mollusc Cyclope neritea (Nassariidae) in France: evidence from mitochondrial sequence data. Mol Ecol 15:1699-1711

Slatkin M, Hudson RR (1991) Pairwise comparisons of mitochondrial-DNA sequences in stable and exponentially growing populations. Genetics 129:555-562

Snell HL, Powell G, Tye A, Bensted-Smith R, Bustamante RH, Branch GM (2002a) Approach to predicting the future of Galápagos biodiversity. In: Bensted-Smith R (ed) A biodiversity vision for the Galápagos Islands. Charles Darwin Foundation and World Wildlife Fund, Puerto Ayora, Galápagos, pp 6-11

Snell HL, Tye A, Causton CE, Bensted-Smith R (2002b) The status of and threats to terrestrial biodiversity. In: Bensted-Smith R (ed) A biodiversity vision for the Galápagos Islands. Charles Darwin Foundation and World Wildlife Fund, Puerto Ayora, Galápagos, pp 30-47

Spencer PB, Yurchenko AA, David VA, Scott R, Koepfli KP, Driscoll C, O'Brien SJ, Menotti-Raymond M (2016) The population 
origins and expansion of feral cats in Australia. J Hered 107:104-114

Stepien CC, Kaczmarek M, Mok H, Stuckert A, Chen P, Downer SJ, Sequeira AS (2010) Isolation and characterization of microsatellite loci for the introduced broad-nosed weevil Galapaganus howdenae howdenae in the Galapágos archipelago. Mol Ecol Resour 10:576-579

Tajima F (1989) Statistical method for testing the neutral mutation hypothesis by DNA polymorphism. Genetics 123:585-595

Therriault TW, Orlova MI, Docker MF, MacIsaac HJ, Heath DD (2005) Invasion genetics of a freshwater mussel (Dreissena rostriformis bugensis) in eastern Europe: high gene flow and multiple introductions. Heredity 95:16-23

Traveset A, Heleno R, Chamorro S, Vargas P, McMullen CK, CastroUrgal R, Nogales M, Herrera HW, Olesen JM (2013) Invaders of pollination networks in the Galápagos Islands: emergence of novel communities. Proc R Soc Lond Ser B Biol Sci 280:20123040

Trucchi E, Facon B, Gratton P, Mori E, Stenseth NC, Jentoft S (2016) Long live the alien: is high genetic diversity a pivotal aspect of crested porcupine (Hystrix cristata) long-lasting and successful invasion? Mol Ecol 25:3527-3539

Tsuchida K, Kudo K, Ishiguro N (2014) Genetic structure of an introduced paper wasp, Polistes chinensis antennalis (Hymenoptera, Vespidae) in New Zealand. Mol Ecol 23:4018-4034

Vera M, Diez-del-Molino D, Garcia-Marin JL (2016) Genomic survey provides insights into the evolutionary changes that occurred during European expansion of the invasive mosquitofish (Gambusia holbrooki). Mol Ecol 25:1089-1105

Wagner DL, Van Driesche RG (2010) Threats posed to rare or endangered insects by invasions of nonnative species. Annu Rev Entomol 55:547-568

Watson J, Trueman M, Tufet M, Henderson S, Atkinson R (2010) Mapping terrestrial anthropogenic degradation on the inhabited islands of the Galápagos Archipelago. Oryx 44:79-82

Weir BS, Cockerham CC (1984) Estimating F-statistics for the analysis of population structure. Evol Int J Org Evol 38:1358-1370

Wood JP, Dowell SA, Campbell TS, Page RB (2016) Insights into the introduction history and population genetic dynamics of the Nile Monitor (Varanus niloticus) in Florida. J Hered 107:349-362

Wu Y, Molongoski JJ, Winograd DF, Bogdanowicz SM, Louyakis AS, Lance DR, Mastro VC, Harrison RG (2015) Genetic structure, admixture and invasion success in a Holarctic defoliator, the gypsy moth (Lymantria dispar, Lepidoptera: Erebidae). Mol Ecol 24:1275-1291

Zane L, Bargelloni L, Patarnello T (2002) Strategies for microsatellite isolation: a review. Mol Ecol 11:1-16

Zenger KR, Richardson BJ, Vachot-Griffin AM (2003) A rapid population expansion retains genetic diversity within European rabbits in Australia. Mol Ecol 12:789-794

Zhang B, Edwards OR, Kang L, Fuller SJ (2012) Russian wheat aphids (Diuraphis noxia) in China: native range expansion or recent introduction? Mol Ecol 21:2130-2144 